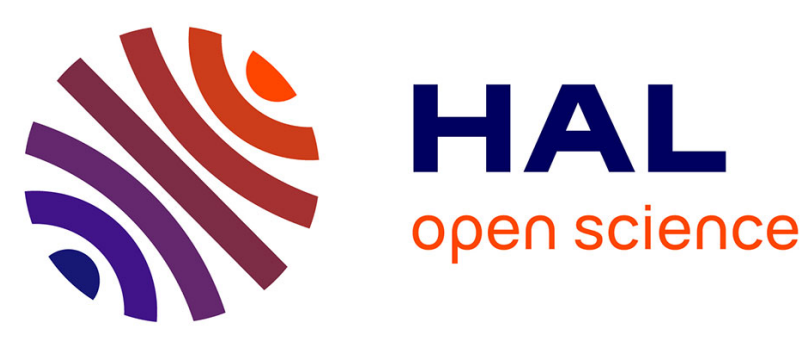

\title{
Evidence for altered dendritic spine compartmentalization in Alzheimer's disease and functional effects in a mouse model
}

Alexandre Androuin, Brigitte Potier, U. Valentin Nägerl, Daniel Cattaert, Lydia Danglot, Manon Thierry, Ihsen Youssef, Antoine Triller, Charles Duyckaerts, Khalid Hamid El Hachimi, et al.

\section{To cite this version:}

Alexandre Androuin, Brigitte Potier, U. Valentin Nägerl, Daniel Cattaert, Lydia Danglot, et al.. Evidence for altered dendritic spine compartmentalization in Alzheimer's disease and functional effects in a mouse model. Acta Neuropathologica, 2018, 135 (6), pp.839-854. 10.1007/s00401-018-1847-6 . hal-02333000

\section{HAL Id: hal-02333000 \\ https://cnrs.hal.science/hal-02333000}

Submitted on 25 May 2021

HAL is a multi-disciplinary open access archive for the deposit and dissemination of scientific research documents, whether they are published or not. The documents may come from teaching and research institutions in France or abroad, or from public or private research centers.
L'archive ouverte pluridisciplinaire HAL, est destinée au dépôt et à la diffusion de documents scientifiques de niveau recherche, publiés ou non, émanant des établissements d'enseignement et de recherche français ou étrangers, des laboratoires publics ou privés. 
Evidence for altered dendritic spine compartmentalization in Alzheimer's disease and functional effects in a mouse model

Alexandre Androuin ${ }^{1,8}$, Brigitte Potier $^{2,3,8}$, U Valentin Nägerl ${ }^{4}$, Daniel Cattaert ${ }^{5}$, Lydia Danglot $^{2}$, Manon Thierry ${ }^{1}$, Ihsen Youssef ${ }^{1}$, Antoine Triller $^{6}$, Charles Duyckaerts ${ }^{1}$, Khalid Hamid El Hachimi ${ }^{1,7}$, Patrick Dutar ${ }^{2,3}$, Benoît Delatour ${ }^{1,9}$, Serge Marty ${ }^{1,9,10}$

${ }^{1}$ Institut du Cerveau et de la Moelle épinière, INSERM U1127, CNRS UMR7225, Université Pierre et Marie Curie, Sorbonne Universités, Paris, France.

${ }^{2}$ Centre de Psychiatrie et Neurosciences, INSERM UMR 894, Université Paris Descartes, Sorbonne Paris Cité, Paris, France.

${ }^{3}$ Present address : Biophotonique et Réseaux Neuronaux, UMR9188 LAC, Université Paris-Sud, Orsay, France

${ }^{4}$ Institut Interdisciplinaire de Neurosciences, CNRS UMR 5297, Université de Bordeaux, Bordeaux, France.

${ }^{5}$ Institut de Neurosciences Cognitives et Intégratives d'Aquitaine, CNRS UMR 5287, Université de Bordeaux, Bordeaux, France

${ }^{6}$ École Normale Supérieure, Institut de Biologie de l'ENS, INSERM, CNRS, PSL Research University, Paris, France

${ }^{7}$ Laboratoire de Neurogénétique, EPHE, PSL Research University, Paris, France

${ }^{8} \mathrm{Co}$-first authors

${ }^{9}$ Co-last authors

${ }^{10}$ Correspondance: serge.marty@icm-institute.org, telephone: +33 15727 45 25, fax: +33 157274784.

\section{Acknowledgments}

We are grateful to Prof. Jean-François Foncin for having established a collection of biopsies taken during neurosurgery (Profs. Le Beau and Philippon) and having provided it to us, and for critical reading of the manuscript. We thank Pascal Barneoud and Laurent Pradier from Sanofi for sharing the APPxPS1-KI mouse line and for stimulating discussions. We also thank Patricia Bassereau for helpful discussions, and Laura Xicota for 
help with statistics. Serge Marty and Alexandre Androuin were supported by a grant from France Alzheimer. The present work was also supported by funding from the program Investissements d'avenir ANR-10-IAIHU-06, ANR-11-INBS-0011-NeurATRIS and the Fondation pour la Recherche Médicale. Antoine Triller was supported by grants from France Alzheimer (Project R12035JJ), the Agence Nationale de la Recherche (ANR-09MNPS-013-01 and ANR-11-BSV8-021-01), the ERC advanced research grant 'PlasltInhib', the program "Investissements d'Avenir" (ANR-10-LABX-54 MEMO LIFE and ANR-11-IDEX-0001-02 PSL* Research University). We also thank the imaging facility of the IBENS, and the imaging facility icm.Quant of the ICM, particularly Dominique Langui and Asha Baskaran for the electron microscopy. This work was partly carried out on the ICM vectorology platform with the help of André Sobczyk, and HISTOMICS platform with the help of Annick Prigent. We also thank the biostatistics facility of the ICM and particularly François-Xavier Lejeune. All animal work was conducted at the ICM PHENOPARC Core Facility. We thank Magali Dumont, Nadège Sarrazin, Delphine Roussel and Joanna Droesbeke from the PHENO.ICMice for their help. 


\section{Abstract}

Alzheimer's Disease (AD) is associated with a progressive loss of synapses and neurons. Studies in animal models indicate that morphological alterations of dendritic spines precede synapse loss, increasing the proportion of large and short ("stubby") spines. Whether similar alterations occur in human patients, and what their functional consequences could be, is not known. We analyzed biopsies from AD patients, and APP $\mathrm{x}$ presenilin 1 knock-in mice that were previously shown to present a loss of pyramidal neurons in the CA1 area of the hippocampus. We observed that the proportion of stubby spines and the width of spine necks are inversely correlated with synapse density in frontal cortical biopsies from non-AD and AD patients. In mice, the reduction in the density of synapses in the stratum radiatum was preceded by an alteration of spine morphology, with a reduction of their length and an enlargement of their neck. Serial sectioning examined with electron microscopy allowed us to precisely measure spine parameters. Mathematical modeling indicated that the shortening and widening of the necks should alter the electrical compartmentalization of the spines, leading to reduced postsynaptic potentials in spine heads, but not in soma. Accordingly, there was no alteration in basal synaptic transmission, but long-term potentiation and spatial memory were impaired. These results indicate that an alteration of spine morphology could be involved in early cognitive deficits associated with AD.

\section{Keywords}

Alzheimer's disease; dendritic spine; synapse; long-term potentiation; amyloid ß; Amyloid Precursor Protein 


\section{Introduction}

Alzheimer's Disease (AD) is the predominant neurodegenerative disorder in the elderly. $\mathrm{AD}$ is characterized by cognitive decline, neurofibrillary degeneration and an accumulation of Amyloid $\beta$ (A $\beta)$, the cleavage product of the Amyloid Precursor Protein (APP). Mutations in the APP gene, or its duplication or mutations in the genes coding for its cleaving enzymes presenilins (PS) 1 or 2 lead to early-onset familial AD (FAD) [50]. Neuronal loss occurs in specific cortical areas and subcortical nuclei in AD [13]. For instance, a massive loss of neurons is observed in the CA1 subfield of the hippocampus [60]. Neuronal loss in CA1 increases with the duration of disease [34]. There is also a loss of synapses and a decrease in the density of dendritic spines along dendrites in several brain areas in $\mathrm{AD}[9-12,16,17,39,46-48]$. A substantial loss of synapses is documented in the CA1 stratum radiatum of patients with mild AD [48]. Loss of synapses in cortical areas correlates with cognitive deficits $[11,47,48,56]$. Thus, AD is proposed to be primarily a synaptopathy [49].

Analysis of synaptic alterations that precede synapse loss could give insights into the underlying pathological mechanism during the very early stages of the pathology. In $\mathrm{AD}$, synapse loss is generally accompanied by an increase in size of the post-synaptic densities (PSDs) of the remaining synapses [11, 41, 46-48]. Since the increase in size of PSDs is proportional to the amount of synapse loss, it is proposed to be a compensatory modification secondary to the disappearance of part of the synapses. To analyze synaptic alterations that could precede synapse loss, transgenic mice overexpressing APP with various FAD mutations have been generated. Similarly to the situation in $\mathrm{AD}$, these mice display a reduction in the density of synapses and of spines along dendrites [1, 30, 35, 39, 41, 53]. The remaining synapses have larger PSDs or higher AMPA receptor content, which could reflect a compensatory response to the loss of synapses [1, 41]. The loss of dendritic spines is preceded by alterations of their morphology. Most spines have a rather thin neck and a bulbous head (mushroom spines); a small proportion has wider necks and lacks a clear head region (stubby spines) [25]. In AD transgenic mice, a higher proportion of stubby spines and shortening of spines have concurrently been reported [37, 44, 55, 63]. However, it is not known if similar alterations of spine shape are present in AD patients. Addressing this question requires a good preservation of spine morphology in brain tissue which is not trivial in human samples (post-mortem delays, non-optimal immersion fixation procedures etc.). Further, the impact of the modifications of spine morphology on 
synapse function remains to be elucidated. Simulation of this impact necessitates precise measurements of spine parameters such as the diameter of spine necks, which are below the resolution of light microscopy [58].

Adequately fixed and embedded frontal biopsies allowed us to examine dendritic spine alterations in $\mathrm{AD}$ and non-AD patients. Their functional consequences were studied using the APPxPS1-KI mouse model of AD that presents a progressive and massive loss of pyramidal neurons in the CA1 area of the hippocampus $[7,8,19]$. We found that the proportion of stubby spines was inversely correlated with the density of synapses in biopsies from $\mathrm{AD}$ and non-AD patients. In mice, serial sectioning examined with electron microscopy allowed us to precisely measure spine parameters, which we used in a biophysical model to simulate their effects on synapse function. We found that the shortening and widening of the necks should alter their electrical compartmentalization, which could explain the deficits in long-term potentiation and spatial memory we measured in the animal model. 


\section{Methods}

\section{Biopsies from $A D$ and non-AD patients}

Brain cortical biopsies collected for diagnostic purpose between 1974 and 1986 were used. Biopsies were taken with a sharp $n^{\circ} 4$ curette from the middle frontal gyrus of the right hemisphere of $\mathrm{AD}$ patients ( $\mathrm{n}=3$; gender: $M$; age (mean +/-SD): $60+/-5$ years), and nonAD patients ( $n=5$ cases; 4 had normal pressure hydrocephalus and 1 had a brain hemorrhage; gender: 4M/1F; age (mean +/-SD): $56+/-11$ years). One of the AD patients had a familial form of AD (M146L mutation of the presenilin 1 gene) [52]. The biopsies were immediately fixed in Karnovsky's solution, postfixed in osmium and embedded in Araldite [17, 18].

\section{Mice}

The APPxPS1-KI mice contain both an APP transgene bearing the Swedish K670N/M671L and London V717I APP mutations under the control of a Thy1 promoter, and M233T and L235P mutations knocked-in into the endogenous presenilin-1 gene [8]. Compared to the single APP transgenic or PS1-KI mice, the APPxPS1-KI line develops an early-onset neuropathological phenotype, including an accelerated formation of intracellular $A \beta$ inclusions, extracellular amyloid deposits and a specific neuronal loss. PS1-KI littermates, which do not develop behavioral-cognitive deficits and in which no loss of hippocampal neurons has been detected, were used as controls as in previous studies $[8,19,62]$. A total of 60 mice, aged between three and six months, were used for this study. Electron microscopy (EM) studies were carried out in three, four and six months-old mice. Electrophysiological and behavioral analyses were performed at the age of three months $+/$ - one week.

The general health of the mice was regularly checked during the course of experimentation. All experiments on animals were conducted in accordance with the ethical standards of French and European laws (European Communities Council Directive $2010 / 63 / \mathrm{EU}$ on the protection of animals used for scientific purposes). The project was approved by the local ethics Committee (Charles Darwin Committee; project $N^{\circ}$ 643.01).

\section{Aldehyde fixation and embedding of mice tissue}

Mice were analyzed with electron microscopy (EM) either at the age of 3, 4 and 6 months ( $n=4$ animals for each genotype and age condition). All mice received an overdose of sodium pentobarbital $(120 \mathrm{mg} / \mathrm{kg})$ and transcardial perfusion was performed with $\mathrm{PB}$ 
containing 2\% paraformaldehyde and $2 \%$ glutaraldehyde. After 1 hour at $4{ }^{\circ} \mathrm{C}$, the brain was extracted from the skull and postfixed in the same fixative for $4 \mathrm{~h}$ at $4^{\circ} \mathrm{C}$. Two hundred- $\mu$ m-thick sections of the right hemisphere were cut in PBS with a Vibratome.

Two frontal sections located in the middle part of the dorsal hippocampus were collected in PBS. They were transferred into an osmium solution for one hour. After several washes, they were stained "en bloc" with a uranyl acetate solution for one hour. After several washes, the samples were dehydrated in graded ethanol followed by acetone. They were incubated in progressive concentrated epoxy resin before being embedded in pure resin.

\section{Preparation and examination of the sections}

Layers II-III of frontally oriented human cortical biopsies were located on semithin sections $(0.5 \mu \mathrm{m}$ thick). Seventy-nm-thick ultrathin sections were collected on copper grids for EM analysis. Serial ultrathin sections were collected on formvar-coated nickel slots grids.

In the mice, semithin sections perpendicular to the long axis of the hippocampus were obtained for light microscopy analysis. Ultrathin sections were collected on 400 mesh copper grids for EM analysis. Other blocks were serially cut perpendicularly to the apical dendrites of CA1 pyramidal neurons to reconstruct their shape in 3D. Dendrites located at a distance of 50-100 $\mu \mathrm{m}$ from the cell body of the pyramidal neurons were selected for the reconstruction. Series of 33 to 65 ultrathin sections were collected on formvar-coated nickel slots grids.

Semithin sections were stained with $0.5 \%$ toluidine blue. Ultrathin sections were contrasted by incubation with 5\% uranyl acetate followed by lead citrate for 5 min each, and were analyzed either with a Philips TECNAI 12 (FEI, Eindhoven, the Netherlands) or with a Hitachi HT 7700 (Elexience, Verrieres le Buisson, France) electron microscope.

\section{Quantifications}

Measurements were done on photomicrographs using the Image J software [45], and blind to pathology or genotype. When counting was performed in a frame the rule of the excluded sides was applied: the objects crossing the upper and right sides of the rectangle were not counted while those intersecting the lower and left side were counted [23]. The mean value per human patient or mouse was then calculated.

Quantifications in biopsies were performed in layers II-III of the right middle frontal gyrus. The number of synaptic profiles on spines was counted in a $53 \mu \mathrm{m}^{2}$ square. 
Eighty measurements were performed in one ultrathin section (every two fields, random starting point). The number of stubby spines entirely in the plane of the section, and the neck diameter of dendritic spines entirely in the plane of the section were measured on the same photomicrographs.

Quantifications in mice were performed in the middle of the CA1 subfield of the hippocampus. The number of neuronal nuclei profiles in the pyramidal layer was counted in a $220 \times 158 \mu \mathrm{m}$ rectangle on three semithin sections $15 \mu \mathrm{m}$ apart. The area of neuronal nuclei profiles in the pyramidal layer was counted in a $220 \times 158 \mu \mathrm{m}$ rectangle on one semithin section. The height of the stratum radiatum was measured on three semithin sections $15 \mu \mathrm{m}$ apart. The number of synaptic profiles on spines in the stratum radiatum was counted in a $29 \mu \mathrm{m}^{2}$ square at $50-100 \mu \mathrm{m}$ from the pyramidal layer. A mean of 35 measurements were performed in one ultrathin section (every two fields in two squares of the 400-mesh grid). The length of 100 postsynaptic densities (PSDs) and the neck diameter of dendritic spines entirely in the plane of the section were measured on the same photomicrographs.

For 3D reconstruction of dendritic spines, photomicrographs were taken at 16,500fold magnification on the serial sections. Dendrites running perpendicular to the plane of section were randomly selected and all their spines were reconstructed using the Reconstruct software [20]. A total of 50 spines were reconstructed per mouse. The mean spine and spine head volume, spine length, and spine neck length and diameter were calculated for each animal.

\section{Numerical simulations}

We found an increase of the diameter of spine necks in APPxPS1-KI mice, which should reduce their electrical resistance [57]. We intended to determine if and how this change could influence synaptic potentials in the head of the spine and in the soma. For that purpose, we simulated the effects of varying neck diameter on membrane depolarization using a model neuron.

The simulation environment NEURON (version 7.4) [26] was used to build a compartmental model consisting of a soma (diameter: $15 \mu \mathrm{m}$, length: $42 \mu \mathrm{m}$ ), an apical dendrite (length: $500 \mu \mathrm{m}$; proximal diameter: $4 \mu \mathrm{m}$; distal diameter: $0.4 \mu \mathrm{m}$ ), on which a spine (diameter of spherical head: $0.564 \mu \mathrm{m}$; length of spine neck: $0.8 \mu \mathrm{m}$; diameter of spine neck: $0.098-0.27 \mu \mathrm{m}$; $\mathrm{R}_{\text {neck: }} 10-640 \mathrm{M} \Omega$ ) was inserted at a distance of $50 \mu \mathrm{m}$ from the soma. In each section, the number of segments was an odd number calculated 
according to the d-lambda rule [27], which ensures that the length of each segment is short enough to compute fast capacitive transmembrane currents. In NEURON the lambda rule is defined by two parameters: frequency set to $1000 \mathrm{~Hz}$ and d-lambda set to 0.03 adapted to fast spike kinetics.

All compartments had the same specific membrane resistance $\left(\mathrm{R}_{\mathrm{m}}\right)$ set to $13600 \Omega$ $\times \mathrm{cm}^{2}$ (specific leak conductance: $73.53 \mu \mathrm{S} / \mathrm{cm}^{2}$ ). All computations were carried out assuming a specific capacitance, $\mathrm{C}_{\mathrm{m}}$, of $1 \mu \mathrm{F} / \mathrm{cm}^{2}$ and a specific cytoplasmic resistance, $\mathrm{R}_{\mathrm{a}}$, of $150 \Omega \times \mathrm{cm}$. Excitatory synaptic currents were simulated using exponential functions (rise time constant $\tau_{1}=0.2 \mathrm{~ms}$ and decay time constant $\tau_{2}=3 \mathrm{~ms}$ ), with a maximal synaptic conductance of $1 \mathrm{nS}$ and a reversal potential of $0 \mathrm{mV}$. The resting potential was set to $\mathrm{V}_{\text {rest }}$ $=-80 \mathrm{mV}$ by adjusting the reversal potential of the leak conductance.

The temporal integration step was $20 \mu$ s. In series of simulations, the electrical resistance imposed by the spine neck was set to $10,20,40,80,160,320$, and $640 \mathrm{M} \Omega$ by adjusting the diameter of the spine neck. The resulting simulated EPSPs were measured in the spine head and in the soma.

\section{Ex vivo electrophysiology}

Electrophysiological experiments were performed in PS1-KI ( $n=8)$ and APPxPS1-KI ( $n=8)$ mice at the age of 3 months. PS1-KI and APPxPS1-KI mice were deeply anesthetized with isoflurane and sacrificed alternately one per day. The brain was rapidly removed from the skull and placed in a chilled $\left(0-3^{\circ} \mathrm{C}\right)$ artificial cerebrospinal fluid (ACSF) containing (mM) $\mathrm{NaCl}$ 124, $\mathrm{KCl} 3.5, \mathrm{MgSO} 4$ 1.5, $\mathrm{CaCl} 2$ 2.5, NaHCO3 26.2, NaH2PO4 1.2, glucose 11. Transverse slices (300-400 $\mu \mathrm{m}$ thick) were cut using a vibratome (Leica VT1200S), and placed in a holding chamber (at $27^{\circ} \mathrm{C}$ ) containing the ACSF solution for at least one hour before recording. Each slice was individually transferred to a recording chamber and submerged with ACSF continuously superfused and equilibrated with 95\% O2, 5\% CO2 at room temperature. Experiments were performed in the dendritic field of the CA1 area following the stimulation of Schaffer collaterals/commissural pathway located in the stratum radiatum. Recordings of presynaptic fiber volley (PFV) and field excitatory postsynaptic potentials (fEPSPs), mostly resulting from the activation of AMPA receptors, construction of Input/Output (I/O) curves assessing the responsiveness of AMPA/Kainate glutamate receptor, and measure of paired-pulse facilitation (PPF) induced by paired-pulse stimulation with inter-stimulus intervals of $40 \mathrm{~ms}$ have been previously described in details [43]. Long-term potentiation (LTP) was induced by theta-burst stimulation, consisting of 
five trains of four $100 \mathrm{~Hz}$ pulses each, separated by $200 \mathrm{~ms}$ and delivered at test intensity (repeated four times with an interburst interval of $10 \mathrm{~s}$ ). Testing with a single pulse was then resumed at $0.33 \mathrm{~Hz}$ for $60 \mathrm{~min}$. Long-term depression (LTD) was induced by applying a low frequency stimulation at $2 \mathrm{~Hz}(1200$ pulses for $10 \mathrm{~min})$ after collecting $15 \mathrm{~min}$ of stable baseline responses at $0.33 \mathrm{~Hz}$, and recorded for $60 \mathrm{~min}$ after stimulation.

NMDA receptor-mediated fEPSPs were investigated by perfusing slices with low$\mathrm{Mg} 2+(0.1 \mathrm{mM})$ aCSF supplemented with the AMPA/kainate receptor antagonist 2,3dioxo-6-nitro-1,2,3,4-tetrahydrobenzoquinoxaline-7-sulfonamide (NBQX, $10 \mu \mathrm{M}$ ) for 20 $\min$.

Whole-cell patch-clamp recordings of CA1 pyramidal neurons were performed at room temperature, using borosilicate patch pipettes $(5 \mathrm{M} \Omega$ ) filled with $\mathrm{CsCH} 4 \mathrm{O} 3 \mathrm{~S} 140$ mM, CsCl 6 mM, MgCl2 2mM, HEPES 10 mM, EGTA 1,1 mM, QX-314 5 mM, ATP 4 $\mathrm{mM},(\mathrm{pH} 7.3 ; 300$ mosm). Transmembrane currents were acquired and filtered by an amplifier (AxoPatch 1-D, Axon Instruments), stored on a computer and digitalized using the WinLTP software [3] for on-line and off-line analysis. Miniature spontaneous excitatory post-synaptic currents (mEPSCs) were recorded from CA1 pyramidal neurons in APPxPS1 KI ( $n=15$ from 8 mice) and PS1 KI mice $(n=18$ from 8 mice $)$ in the continuous mode at holding potential $(\mathrm{hp})=-60 \mathrm{mV}$. Recordings were made in the presence of tetrodotoxin $(\mathrm{TTX} ; 1 \mu \mathrm{M})$ to abolish action potentials and hence inhibit synaptic transmission, and bicuculline $(10 \mu \mathrm{M})$ to selectively antagonize GABA transmission through GABAA receptors. Frequency and amplitude of mEPSCs occurrence were measured using Spike 2 (CED, Cambridge). Membrane resistance was recorded from CA1 neurons in APPxPS1-KI $(\mathrm{n}=15$ from 8 mice $)$ and PS1-KI mice $(\mathrm{n}=21$ from 8 mice) and calculated at the steady-state of a $-10 \mathrm{mV}$ step $(70 \mathrm{msec})$ from $\mathrm{hp}=-60 \mathrm{mV}$.

\section{Cognitive evaluation}

The apparatus consisted of a square open field $(50 \times 50 \mathrm{~cm})$ placed in a room with weak controlled luminosity ( 8 Lux) and constant $60 \mathrm{~dB}$ white noise. Visual inserts with distinct features were placed on the internal walls of the arena to provide cues allowing definition of a spatial context.

Nine PS1-KI and 11 APPxPS1-KI mice were evaluated. All the animals were three months old. The first two days (D1-2), they were handled by the experimenter. On the two subsequent days (D3-4), mice were habituated for $10 \mathrm{~min}$ to the empty arena. On Day 5 (D5), four identical objects were placed symmetrically $10 \mathrm{~cm}$ away from the arena corners. 
Mice were free to explore the objects and to habituate to their presence in the arena for 10 min. On the following test day (D6), the mice were placed in the arena containing three never-experienced identical objects distributed in all corners except the south-east one; the mice were allowed to explore the objects for two $10 \mathrm{~min}$ sessions inter-spaced by a $5 \mathrm{~min}$ delay. The mice were then left in their home cage for a 5 min retention interval. To test short-term spatial recognition memory, one of the three familiar objects was displaced to the south east corner location. Mice were free to explore the new configuration for a 10 min period. Detection of spatial change (object displacement) in the environment is classically demonstrated by a spatial bias of mice while exploring objects (increased exploration of the displaced object).

Between each trial the arena and objects were cleaned with $70^{\circ}$ ethanol to reduce olfactory cues. During all sessions mice were monitored using the Any-Maze videotracking software (Stoelting, Wood Dale, USA). An object was automatically considered to be explored when the distance between the nose of the mouse and the object was shorter than $2 \mathrm{~cm}$. Pilot studies indicated that this automatic measure was strongly correlated with the manual scoring of exploratory bouts. The ratio time exploring the displaced object versus total exploring time of objects was calculated and used as a memory index (I; chance level at $33 \%$ ):

$$
I=\frac{O_{d}}{O_{d}+O_{n d 1}+O_{n d 2}} \times 100
$$

$\mathrm{O}_{\mathrm{d}}$ : time spent exploring the displaced object

$\mathrm{O}_{\text {nd1,nd2 }}$ : time spent exploring the two non-displaced objects

\section{Statistical analysis}

For the analysis of human biopsies the linear regressions of the number of synapses on the proportion of stubby spines or on the neck diameter were evaluated. In addition, a resampling approach was adopted to account for the effect of intra-individual sample variation that could possibly affect the predicted correlation. The $95 \%$ confidence interval was computed by Bca bootstrapping [15] with 10000 replicas using the boot.ci function of the $\mathrm{R}$ package 'boot'. For the analysis of mice, between-groups comparisons were performed using two-tailed, paired or unpaired Student's t-tests and statistical significance was set to a $\mathrm{p}$ value $<0.05$. For all morphological data relying on an age $\mathrm{x}$ genotype design, a two-way analysis of variance (ANOVA) was performed followed by planed comparisons 
to assess evolution of studied variables across ages (age factor in the two genotypes) and between groups (genotype factor at the 3 different ages). Note that for the analysis of spine shape, the arcsin function was applied to the fraction of spines with head and headless spines for each animal, followed by 2-way ANOVA. For the analysis of LTP $P$ values were calculated using multivariate ANOVA followed by Tukey's post hoc tests to account for the correlations inherent to repeated measures in electrophysiological recordings. Analyses were performed with Statistica v9-v13 (StatSoft, Inc., Tulsa, OK, USA), GraphPad Prism (GraphPad Software, La Jolla, CA, USA), R version 3.3.2 (https://www.rproject.org) or StatView statistical packages. 


\section{Results}

\section{Correlation of spine density and morphology in human biopsies}

Sections in layers II-III from biopsies of the middle frontal gyrus were studied to determine whether alterations of the morphology of dendritic spines could be detected in AD brains. The ultrastructure was well preserved in the biopsies of either non- $\mathrm{AD}(\mathrm{n}=5)$ or $\mathrm{AD}(\mathrm{n}=3)$ patients, allowing a clear identification of spine synapses (asterisks in Fig. 1a, b). We measured for each case the density of spine synapses. To verify that it is possible to classify spines as stubby or non-stubby based on single sections, we analyzed 22 spines in serial sections. The 10 spines that exhibited a "mushroom" morphology in single sections remained mushroom on the adjacent serial sections (Fig. 1c), while the 12 spines that appeared "stubby" in single sections remained stubby (Fig. 1d). These data confirmed that identification of stubby vs non-stubby spines can reliably be performed from single sections. On single sections, we therefore measured the density of stubby spines and the diameter of the neck for all the spines having their neck and their PSD in the plane of the section (Fig. 1e, f). A significant negative correlation was observed between the density of synapses and the proportion of stubby spines $\left(\mathrm{R}^{2}=0.616, \mathrm{P}=0.021\right.$; Fig. $\left.1 \mathrm{~g}\right)$, and accordingly between the density of synapses and the neck diameter $\left(\mathrm{R}^{2}=0.566, \mathrm{P}=0.031\right)$. Moreover, a resampling approach was adopted to account for the effect of intra-individual sample variation that could possibly affect the predicted correlation. The calculated $95 \%$ bootstrap confidence interval still provided strong evidence of a significant negative correlation to validate the relationship between the density of synapses and the proportion of stubby spines or neck diameter. $\mathrm{s}$

\section{An alteration of the morphology of dendritic spines occurs before the decrease of neuronal and synaptic density in APPXPS1-KI mice}

We aimed then to determine the timing of alteration of dendritic spine morphology with respect to synapse and neuron loss in APPxPS1 KI mice. Previous studies indicated a 20$30 \%$ neuronal loss at 6 months, and a 50\% neuronal loss at 10 months in the CA1 stratum pyramidale of APPxPS1-KI mice [7, 8, 19]. To determine how early a decrease of neuronal density could be detected, the density of neuronal nuclear profiles was quantified on semithin sections, in the pyramidal cell layer of the CA1 subfield in PS1-KI and APPxPS1$\mathrm{KI}$ mice at 3, 4 and 6 months ( $\mathrm{n}=4$ mice per age and per genotype; Fig. 2a, b). ANOVA indicated an overall decrement in neuronal density with increased age $(F(2,18)=5.875)$; 
however this effect was significant in APPxPS1-KI mice $(\mathrm{F}(1,18)=12.557$; $\mathrm{p}<.0025$; Fig. 2c) but not in PS1-KI controls $(F(1,18)=1.633$; ns $)$. Effect of the genotype factor just failed to reach statistical significance $(F(1,18)=3.403 ; p=0.082)$ because neuronal densities were very similar in the two genotypes at 3 and 4 months $(\mathrm{Fs}<1)$ and only showed a $19 \%$ decrement in the oldest APPxPS1-KI mice at 6 months of age $(\mathrm{F}(1,18)=5.399$; $\mathrm{p}<.05$ ). Because changes in the size of neuronal nuclei could have induced a stereological bias in the neuron count, we verified that the surface area of nuclear profiles was similar between genotypes (data not shown).

To determine if synaptic alterations in the stratum radiatum could precede neuronal loss, we first measured the width of the stratum radiatum (Double arrows in Fig. 2a, b). ANOVA underlined a significant effect of both genotype $(F(1,18)=18.665 ; \mathrm{p}<.001)$ and age $(F(2,18)=17.657 ; \mathrm{p}<.001)$ factors (Fig. 2d). Once again, an age-dependent atrophy of the stratum radiatum was observed in APPxPS1-KI mice $(\mathrm{F}(1,18)=69.682 ; \mathrm{p}<.001)$ but not in PS1-KI mice $(\mathrm{F}<1)$. Mirroring observations on neuronal densities, no differences between genotypes were noted at 3 and 4 months ( $\mathrm{Fs}<1)$ while APPxPS1-KI mice showed a $27 \%$ reduction of the stratum radiatum width at 6 months $(F(1,18)=60.047 ; p<.001)$.

The density of excitatory, asymmetric synaptic profiles on dendritic spines was then quantified using EM at 50-100 $\mu \mathrm{m}$ from the pyramidal cell layer $(\mathrm{n}=4$ mice per age and per genotype; Fig. 2e, f). ANOVA indicated an overall effect of the genotype factor $(F(1,18)=$ $22.143 ; \mathrm{p}<.001$; Fig. $2 \mathrm{~g})$ and of the age factor $(\mathrm{F}(2,18)=12.234 ; \mathrm{p}<.001)$ that was explained by an age-dependent decrease in synapse density in APPxPS1-KI mice $(\mathrm{F}(1,18)=$ $34.031 ; \mathrm{p}<.001)$ but not in PS1-KI controls $(\mathrm{F}(1,18)=1.144 ; \mathrm{ns})$. Subsequent analyses showed a large (-42\%) decrement in synapses density in APPxPS1-KI mice at 6 months of age $(\mathrm{F}(1,18)=31.839 ; \mathrm{p}<.001)$ that was also marginally evidenced at 4 months $(-14 \%$ reduction, $\mathrm{F}(1,18)=3.251 ; \mathrm{p}=0.076)$ but absent in the youngest 3 -months old transgenics $(\mathrm{F}<1)$.

ANOVA on PSD length also showed an effect of genotype $(F(1,18)=15.12$; $\mathrm{p}<.001)$ and Age $(\mathrm{F}(2,18)=11.63 ; \mathrm{p}<.001)$ factors (Fig. 2h). An increase in PSD size was clearly observed between 3 and 6 months in APPxPS1-KI mice $(F(1,18)=38.325 ; \mathrm{p}<.001)$ while PSDs remained unaltered in PS1-KI mice $(\mathrm{F}<1)$. Consequently, differences between genotypes were observed at 4 months $(10 \%$ increase in APPxPS1-KI mice, $\mathrm{F}(1,18)=8.23$; $\mathrm{p}<.025)$ and 6 months $(16 \%$ increase, $\mathrm{F}(1,18)=22.766 ; \mathrm{p}<.001)$, but not at 3 months $(\mathrm{F}<1)$.

The morphology of dendritic spines at 3 months of age was then assessed by measuring the neck diameter of spines in the plane of EM sections (Fig. 2i, j). The neck 
diameter was increased in APPXPS1-KI mice when compared to PS1-KI mice $(28,6 \%$, unpaired Student's t-test: $\mathrm{t}(6)=2.57, \mathrm{P}=0.018$, Fig. $2 \mathrm{k}$ ). Thus, an alteration of spine morphology occurred before the reduction in synapse and neuron density.

\section{D-spine reconstructions to quantify the alterations of spine morphology}

The alterations of spine morphology were precisely quantified using $3 \mathrm{D}$ reconstructions following serial sectioning EM, to be able to simulate the impact of these alterations on the electrical and biochemical compartmentalization of spines (Fig. 3a, b).

Fifty spines were analyzed per mouse, allowing a total of 200 spines per genotype and per time point ( $\mathrm{n}=4$ mice per age and per genotype). Spines were classified as presenting or not a constriction (Fig. 3c) [21]. ANOVA was performed on the proportion of spines with/without constrictions and showed a large effect of the genotype factor $(F(1,18)=46.08 ; p<.001$; Fig. 3d $)$ with no effect of age $(F(2,18)=2.355$; ns $)$. Subsequent analysis underlined that, already at 3 months, there was a $28 \%$ decrease of the number of spines with and a $93 \%$ increase of the number of spines without a constriction in APPxPS1-KI mice when compared to PS1-KI mice (difference between groups: $F(1,18)=$ $19.327 ; \mathrm{p}<.001)$. Similarly at 4 months, there was a $33 \%$ decrease of the number of spines with and a 73\% increase of the number of spines without constriction in APPxPS1-KI mice $(F(1,18)=21.167 ; p<.001)$. At 6 months, the difference was also significant, with a $20 \%$ decrease in the number of spines with and a $41 \%$ increase of the number of spines without constriction $(F(1,18)=7.62 ; \mathrm{p}<.025)$. Thus, an alteration of spine morphology was present at all ages examined.

Several morphological parameters were measured on the electron microscopy 3Dspine reconstructions (Fig. 3e, f). ANOVA on spine volume indicated an overall effect of genotype $(\mathrm{F}(1,18)=9.027 ; \mathrm{p}<.01)$ and age $(\mathrm{F}(2,18)=8.336 ; \mathrm{p}<.01)$ factors (Fig. 3g). APPxPS1-KI mice displayed an age-dependent increase in spine volume $(F(1,18)=12.705$; $\mathrm{p}<.0025)$ while no alterations were depicted in PS1-KI littermates $(\mathrm{F}<1)$. Planed comparisons showed a significant difference between genotypes at 6 months $(F(1,18)=$ 4.574; $\mathrm{p}<.05)$ and 4 months $(\mathrm{F}(1,18)=12.202 ; \mathrm{p}<.01)$ but not at 3 months $(\mathrm{F}<1)$.

Measurements of spine morphology were performed at 3 months to avoid bias due to increased spine volume. In APPxPS1-KI mice the length of dendritic spines was decreased by $15 \%$ (unpaired Student's t-test: $\mathrm{t}(6)=2.81, \mathrm{P}=0.0308$, Fig. $3 \mathrm{~h}$ ) and the diameter of spine necks was increased by $35 \%$ (unpaired Student's t-test: $\mathrm{t}(6)=3.36, \mathrm{P}=$ 0.0153; Fig. 3i), in agreement with the quantification on single sections (Fig. 2k). Thus, at 
3 months the length of dendritic spines is reduced while the diameter of their neck is increased, giving spines a more "stubby" appearance (Fig. 3b).

\section{Simulation of the impact of the changes in spine neck morphology on the electrical and biochemical compartmentalization of spines}

Both, the reduced length and increased width of the spine neck should reduce its electrical resistance [57]. We estimated the electrical resistance of spine necks on the basis of neck morphology using Ohm's law:

$$
R=\frac{\rho L}{A}
$$

where $\rho$ is the resistivity of the cytoplasm, L the length and A the cross-sectional area of the spine neck [57]. There was a 43\% reduction of the neck resistance in APPxPS1-KI mice (unpaired Student's t-test: $\mathrm{t}(6)=2.6291, \mathrm{P}=0.0391$; Fig. 4a).

We then simulated the potential effects of the modification of spine neck resistance on EPSPs in spine heads and somas (Fig. 4b; see Methods). Decreasing the spine neck resistance by $50 \%$ had very little impact on simulated EPSP amplitudes measured at the level of the cell body, largely irrespective of the initial resistance (Fig. 4c). However, the same drop in neck resistance substantially affected the EPSP in the spine head for neck resistances initially larger than $80 \mathrm{M} \Omega$ (Fig. 4c).

The reduced length and increased diameter of necks in APPxPS1-KI mice should also alter the diffusion of molecules across the spine neck [58]. We estimated the diffusional coupling between the spine head and the dendritic shaft:

$$
\tau=\frac{\mathrm{VL}}{\mathrm{DA}}
$$

where $\tau$ is the time constant of diffusional equilibration across the spine neck for a particular molecule, $\mathrm{V}$ is the volume of the spine head, $\mathrm{L}$ the length, A the cross-sectional area of the spine neck, and D the diffusion coefficient of the molecule [57]. For spines without constriction, the head volume was estimated using the diameter of the spine. There was a 52\% reduction of the time constant in APPxPS1-KI mice (unpaired Student's t-test: $\mathrm{t}(6)=2.8443$, $\mathrm{P}=0.0294$; Fig. 4d), indicating a steep reduction in the biochemical compartmentalization of spines. 


\section{Maintenance of basal parameters of synaptic function}

The simulation predicted no reduction of EPSPs in cell bodies, suggesting that basal parameters of synaptic function could be maintained. We performed electrophysiological recordings in the CA1 subfield at 3 months to study these basal parameters. Following stimulation of Schaffer collaterals, we observed no alteration of the afferent volley slope, of the field excitatory postsynaptic potentials (fEPSPs; PS1-KI, $n=45$ slices from 8 mice and APPXPS1-KI, n=39 slices from 8 mice; Fig. 5a, b) or of the paired-pulse facilitation (PS1-KI, $1.54 \pm 0.03, \mathrm{n}=48$ slices from 8 mice and APPxPS1-KI, $1.50 \pm 0.03, \mathrm{n}=43$ slices from 8 mice; Fig. 5c), suggesting that presynaptic axon excitability and presynaptic release probability were not altered in APPxPS1-KI mice. There was also no significant modification of the amplitude of NMDA-dependent fEPSPs (PS1-KI, $n=11$ slices from 4 mice and APPxPS1-KI, $\mathrm{n}=19$ slices from 4 mice; see curve Fig. 5d). Patch clamp recordings of CA1 pyramidal neurons showed no alteration of the amplitude $(13.7 \pm 0.6$ pA in PS1-KI, $\mathrm{n}=18$ cells from 8 mice vs $14.0 \pm 0.9$ pA in APPxPS1-KI, $\mathrm{n}=15$ cells from 8 mice), or frequency $(0.67 \pm 0.08 \mathrm{~Hz}$ in PS1-KI, $\mathrm{n}=18$ cells from 8 mice vs $0.65 \pm 0.07 \mathrm{~Hz}$ in APPxPS1-KI, $\mathrm{n}=13$ cells from 8 mice) of miniature excitatory postsynaptic currents (mEPSCs) dependent on the activation of AMPA receptors (Fig. 5e, f). Whole-cell membrane resistance was not changed in both genotypes $(206.6 \pm 10.3 \mathrm{M} \Omega$ in PS1-KI, $\mathrm{n}=21$ cells from 8 mice vs $191.6 \pm 11.6 \mathrm{M} \Omega$ in APPxPS1-KI, $\mathrm{n}=15$ cells from 8 mice; Fig. $5 \mathrm{~g})$. Thus, the spontaneous or evoked release of glutamate and synaptic AMPA and NMDA currents did not appear modified.

\section{Early deficit in long-term potentiation}

The simulation predicted a reduction of EPSPs in spine heads that could potentially affect the plasticity of dendritic spines. We analyzed synaptic plasticity in the CA1 subfield at 3 months to determine if such alteration occurred in APPxPS1-KI mice. The significance of LTP expression was determined by comparing the $15 \mathrm{~min}$ of baseline recordings with values recorded between 45 and $60 \mathrm{~min}$ after the conditioning stimulation. The significance of changes in LTP magnitude between groups was determined by comparing the last $15 \mathrm{~min}$ of recordings. A deficit in LTP was observed following theta-burst stimulation of Schaffer collaterals (Fig. 6a). Applying stimulation induced a potentiation of synaptic responses much lower in APPxPS1-KI mice $(115.9 \pm 7.5 \%$ of baseline, $n=14$ slices from 8 mice) as compared to PS1-KI mice (139.8 $\pm 5.2 \%$ of baseline, $n=13$ slices 
from 8 mice). The difference was statistically significant $(\mathrm{F}(1,25)=6.8, \mathrm{P}=0.014)$. A statistically significant difference was also observed during the first 3 minutes after stimulation, indicating an alteration of LTP induction $(\mathrm{F}(1,25)=5.3, \mathrm{P}=0.03)$. However, LTD following low frequency stimulation of Schaffer collaterals was not modified in APPxPS1-KI (Fig. 6b). The low frequency stimulation applied at 2-Hz (1200 pulses), induced a comparable depression of synaptic responses in slices from PS1-KI $(80.3 \pm 4.8 \%$ of baseline, $\mathrm{n}=10$ slices from 8 mice) and in slices from APPxPS1-KI (77.9 $\pm 4.0 \%$ of baseline, $\mathrm{n}=8$ slices from 8 mice; $\mathrm{F}(1,16)=0.15, \mathrm{P}=0.7)$. Thus, there was a specific deficit in LTP at 3 months, concomitant with the alteration of spine morphology.

\section{Early deficit in spatial memory}

Synaptic plasticity is currently believed to underlie learning and memory. Therefore, we determined whether cognitive deficits could be present at 3 months by studying the shortterm spatial recognition memory. For that purpose, we used a novel object location (NOL) paradigm. During acquisition mice spent much time exploring the objects. This was observed both in PS1-KI ( $n=9$ mice; mean $=202 \mathrm{sec}$. of exploration cumulated on the 3 objects, minimum $=134 \mathrm{sec} .$, maximum $=311 \mathrm{sec}$. $)$ and in APPxPS1-KI mice $(\mathrm{n}=11$ mice; mean $=189$ sec., minimum $=113$ sec., maximum $=266$ sec.). Importantly similar levels of exploration were noted in the two genotypes (unpaired Student's t-test: $t(18)=0.57$, ns) indicating comparable exposition to the stimuli to be memorized. Five minutes after acquisition mice were replaced in the arena for the memory retention test (Fig. 6c; see Methods). When exploration levels were compared to chance level (33\% of exploration on each objects), PS1-KI mice significantly preferred the displaced object (paired Student's ttest: $\mathrm{t}(8)=8.156 ; \mathrm{p}<0.0001)$ while APPxPS1-KI mice did not $(\mathrm{t}(10)=1.927$; ns). APPxPS1KI mice demonstrated a lower memory index when compared to control PS1-KI mice (unpaired Student's t-test: t $(18)=3.5017 ; \mathrm{p}<0.005$; Fig. 6d) indicative of an important recognition memory deficit in this genotype at 3 months. 


\section{Discussion}

In biopsies from non-AD and $\mathrm{AD}$ patients, we observed that a lower density of synapses was associated with an increased proportion of stubby spines and an enlargement of spine necks. We complemented our analysis in transgenic mice to study the potential functional consequences of the alteration of spine morphology. In APPxPS1 KI mice we observed a reduction in the density of synapses in the CA1 stratum radiatum, consistent with the synapse loss described in $\mathrm{AD}[9,11,47-49,56]$. The enlargement of PSDs of the remaining spines observed in APPXPS1-KI mice also matched observations in the human disease $[47,48]$, potentially reflecting a compensatory, "homeostatic" regulation of the size of PSDs [28]. Additionally, the enlargement of PSDs may be due to a preferential loss of synapses with small PSDs. The size of the PSD is correlated with the volume of the dendritic spine [24]. Accordingly, we observed that an increased volume of the remaining spines accompanied the enlargement of PSDs. We also observed an alteration of dendritic spine morphology that preceded the loss of synapses and neurons. There was a reduction in the length of spines and an enlargement of their neck, giving spines a more "stubby" appearance. Thus, the APPxPS1 KI mouse model recapitulated several aspects of the synaptopathy observed in AD. It is in agreement with previous studies showing that transgenic mice overexpressing FAD mutations present a loss of synapses [1, 30, 35, 39, 41, 53], an enlargement of PSDs [1], and an increased proportion of stubby spines [44, 54, $55,63]$. It gave us the opportunity to study the potential effects of the early alterations of spine morphology on synapse function.

We combined electrophysiological and behavioral studies with numerical simulations to analyze the potential functional consequences of the first alterations of dendritic spine morphology in APPxPS1-KI mice. The only alteration of synaptic function that we could detect with electrophysiology was a deficit in LTP, which was accompanied by an alteration of spatial memory. While previous studies described deficits in LTP and spatial memory in APPxPS1 KI mice at later stages, when synapse and neuron loss is in full effect [7, 19], we could detect them already before the loss of synaptic and cellular structures. LTP is dependent on calcium influx through NMDA receptors [29]. However, there was no reduction of the amplitude of NMDA-dependent fEPSPs. Similarly a recent study on another APP transgenic mouse line found no alteration of NMDA currents [59]. A shift of the LTP/LTD threshold in favor of LTD could explain the reduced LTP, and also the later loss of synapses $[40,61]$. However, we found neither an evidence for a decrease 
in basal synaptic transmission, nor an increase in LTD in APPxPS1-KI mice. LTP increases the diameter of spine necks [57]. Thus, the deficit in LTP in APPxPS1 KI mice cannot be responsible for the enlargement of spine necks. On the contrary, the abnormal morphology of spines could reduce LTP in a reverse causality. Even though the simulation suggests that the observed changes in spine morphology are unlikely to substantially affect EPSPs in the cell body, they might reduce EPSPs in the spine head and thus prevent the depolarization required for the induction of synaptic plasticity, especially for spines where the neck resistance was initially high. The effect of the alteration of spine morphology on LTP therefore depends critically on the size of the electrical resistance of spine necks, which remains debated $[6,58]$. In addition to this electrical effect, the changes in spine morphology should diminish the diffusional isolation of the spine head from the dendritic shaft [58]. This reduced spine compartmentalization could reduce LTP induction by preventing a sufficient built-up of messenger molecules or activated proteins as they diffuse out of the spines more easily [2, 42].

The links between LTP and experience-dependent brain functions, such as learning and memory functions, have been repeatedly stressed [36]. LTP relies indeed on synaptic remodeling that could serve as the substratum for cellular changes responsible for the formation of memories. Anomalies of LTP are generally associated with cognitive impairments and, in the present study, we depicted a severe deficit in spatial recognition memory in 3-months old APPxPS1-KI mice concomitant to abnormal LTP in the same transgenics. The decrement in memory functions observed in young APPxPS1-KI mice can be paralleled by clinical observations: subjects with moderate AD or even mild cognitive impairments display graded deficits in recognition memory tasks [5]. The whole set of our data therefore suggests that the very initial morphological changes tackling dendritic spines in $\mathrm{AD}$ brains could trigger local synaptic plasticity alterations and subsequently the early clinical manifestations of the disease (recognition memory impairments).

Both, the reduction of the length of dendritic spines and the enlargement of their neck can be explained by a decrease of the forces exerted by the spine cytoskeleton on the plasma membrane [38]. It is thus conceivable that the early change in spine morphology in APPxPS1-KI mice is due to an alteration of the underlying cytoskeleton. The spine cytoskeleton is made of actin and spectrin filaments that are important for the maintenance of dendritic spines [14, 31,33]. Additionally, periodic actin structures are observed at the spine neck [4]. A recent study describes an early decrease of actin polymerization in synaptosomes of another transgenic mouse model of AD [32]. It could be due to the 
alteration of various signaling pathways in dendritic spines $[22,51]$. The mechanism of cytoskeleton alteration, and whether it affects synaptic plasticity and maintenance, remains to be investigated. 


\section{References}

1. Alonso-Nanclares L, Merino-Serrais P, Gonzalez S, DeFelipe J (2013) Synaptic changes in the dentate gyrus of APP/PS1 transgenic mice revealed by electron microscopy. $\mathrm{J}$ Neuropathol Exp Neurol 72:386-395

2. Alvarez VA, Sabatini BL (2007). Anatomical and Physiological Plasticity of Dendritic Spines. Annu Rev Neurosci 30:79-97

3. Anderson WW, Collingridge GL (2001). The LTP Program: a data acquisition program for on-line analysis of long-term potentiation and other synaptic events. J Neurosci Methods 108:71-83

4. Bär J, Kobler O, van Bommel B, Mikhaylova M (2016) Periodic F-actin structures shape the neck of dendritic spines. Sci Rep 6:37136

5. Barbeau E, Didic M, Tramoni E, Felician O, Joubert S, Sontheimer A, Ceccaldi M, Poncet M (2004) Evaluation of visual recognition memory in MCI patients. Neurology 62:1317-1322

6. Beaulieu-Laroche L, Harnett MT (2018) Dendritic spines prevent synaptic voltage clamp. Neuron 97:75-82

7. Breyhan H, Wirths O, Duan K, Marcello A, Rettig J, Bayer TA (2009). APP/PS1KI bigenic mice develop early synaptic deficits and hippocampus atrophy. Acta Neuropathol 117:677-685

8. Casas C, Sergeant N, Itier J-M, Blanchard V, Wirths O, van der Kolk N, Vingtdeux V, van de Steeg E, Ret G, Canton T, Drobecq H, Clark A, Bonici B, Delacourte A, Benavides J, Schmitz C, Tremp G, Bayer TA, Benoit P, Pradier L (2004). Massive CA1/2 neuronal loss with intraneuronal and N-terminal truncated Abeta42 accumulation in a novel Alzheimer transgenic model. Am J Pathol 165:1289-1300

9. Davies CA, Mann DM, Sumpter PQ, Yates PO (1987). A quantitative morphometric analysis of the neuronal and synaptic content of the frontal and temporal cortex in patients with Alzheimer's disease. J Neurol Sci 78:151-164

10. de Ruiter JP, Uylings HB (1987) Morphometric and dendritic analysis of fascia dentata granule cells in human aging and senile dementia. Brain Res 402:217-229

11. DeKosky ST, Scheff SW (1990). Synapse loss in frontal cortex biopsies in Alzheimer's disease: correlation with cognitive severity. Ann Neurol 27:457-464

12. Domínguez-Álvaro M, Montero-Crespo M, Blazquez-Llorca L, Insausti R, DeFelipe J, Alonso-Nanclares L (2018) Three-dimensional analysis of synapses in the transentorhinal cortex of Alzheimer's disease patients. Acta Neuropathol Commun 6:20

13. Duyckaerts C, Delatour B, Potier M-C (2009). Classification and basic pathology of Alzheimer disease. Acta Neuropathol 118:5-36

14. Efimova N, Korobova F, Stankewich MC, Moberly AH, Stolz DB, Wang J, Kashina A, Ma M, Svitkina T (2017) $\beta$ III Spectrin Is Necessary for Formation of the Constricted 
Neck of Dendritic Spines and Regulation of Synaptic Activity in Neurons. J Neurosci 37:6442-6459

15. Efron B (1987). Better Bootstrap Confidence Intervals. J Am Stat Assoc 82:171-185

16. Einstein G, Buranosky R, Crain BJ (1994) Dendritic pathology of granule cells in Alzheimer's disease is unrelated to neuritic plaques. J Neurosci 14:5077-5088

17. El Hachimi KH, Foncin J-F (1990). Loss of dendritic spines in Alzheimer's disease. C R Acad Sci III 311:397-402

18. El Hachimi KH, Verga L, Giaccone G, Tagliavini F, Frangione B, Bugiani O, Foncin JF (1991). Relationship between non-fibrillary amyloid precursors and cell processes in the cortical neuropil of Alzheimer patients. Neurosci Lett 129:119-122

19. Faure A, Verret L, Bozon B, El Tannir El Tayara N, Ly M, Kober F, Dhenain M, Rampon C, Delatour B (2011). Impaired neurogenesis, neuronal loss, and brain functional deficits in the APPxPS1-Ki mouse model of Alzheimer's disease. Neurobiol Aging 32:407-418

20. Fiala JC (2005). Reconstruct: a free editor for serial section microscopy. J Microsc 218:52-61

21. Fiala JC, Spacek J, Harris KM (2008). Dendrite structure. In: Stuart G, Spruston N, Häusser M (eds) Dendrites, 2nd edn. Oxford University Press, Oxford, pp 1-40

22. Fu AK, Ip NY (2017) Regulation of postsynaptic signaling in structural synaptic plasticity. Curr Opin Neurobiol 45:148-155

23. Gundersen HJ, Bendtsen TF, Korbo L, Marcussen N, Møller A, Nielsen K, Nyengaard JR, Pakkenberg B, Sørensen FB, Vesterby A (1988). Some new, simple and efficient stereological methods and their use in pathological research and diagnosis. APMIS 96:379-394

24. Harris KM, Stevens JK (1989). Dendritic spines of CA 1 pyramidal cells in the rat hippocampus: serial electron microscopy with reference to their biophysical characteristics. J Neurosci 9:2982-2997

25. Harris KM, Jensen FE, Tsao B (1992). Three-dimensional structure of dendritic spines and synapses in rat hippocampus (CA1) at postnatal day 15 and adult ages: implications for the maturation of synaptic physiology and long-term potentiation. J Neurosci 12:2685-2705

26. Hines ML, Carnevale NT (1997). The NEURON simulation environment. Neural Comput 9:1179-1209

27. Hines ML, Carnevale NT (2001) NEURON: a tool for neuroscientists. The Neurocientist 7:123-135

28. Horellou S, Pascual O, Triller A, Marty S (2014). Adaptive and non-adaptive changes in activity-deprived presynaptic terminals. Eur J Neurosci 39:61-71 
29. Huganir RL, Nicoll RA (2013). AMPARs and Synaptic Plasticity: The Last 25 Years. Neuron 80:704-717

30. Jacobsen JS, Wu,C-C, Redwine JM, Comery TA, Arias R, Bowlby M, Martone R, Morrison JH, Pangalos MN, Reinhart PH, Bloom FE (2006). Early-onset behavioral and synaptic deficits in a mouse model of Alzheimer's disease. Proc Natl Acad Sci USA 103:5161-5166

31. Kim IH, Racz B, Wang H, Burianek L, Weinberg R, Yasuda R, Wetsel WC, Soderling SH. (2013) Disruption of Arp2/3 results in asymmetric structural plasticity of dendritic spines and progressive synaptic and behavioral abnormalities. J Neurosci 33:6081-6092

32. Kommaddi RP, Das D, Karunakaran S, Nanguneri S, Bapat D, Ray A, Shaw E, Bennett DA, Nair D, Ravindranath V (2018) A $\beta$ mediates F-actin disassembly in dendritic spines leading to cognitive deficits in Alzheimer's disease. J Neurosci 38:1085-1099

33. Korobova F, Svitkina T (2010) Molecular architecture of synaptic actin cytoskeleton in hippocampal neurons reveals a mechanism of dendritic spine morphogenesis. Mol Biol Cell 21:165-176

34. Kril J, Patel S, Harding A, Halliday G (2002). Neuron loss from the hippocampus of Alzheimer's disease exceeds extracellular neurofibrillary tangle formation. Acta Neuropathol 103:370-376

35. Lanz T, Carter D, Merchant K (2003). Dendritic spine loss in the hippocampus of young PDAPP and Tg2576 mice and its prevention by the ApoE2 genotype. Neurobiol Dis 13:246-253

36. Lynch MA (2004) Long-term potentiation and memory. Physiol rev 84:87-136.

37. Merino-Serrais P, Knafo S, Alonso-Nanclares L, Fernaud-Espinosa I, DeFelipe J (2011). Layer-specific alterations to CA1 dendritic spines in a mouse model of Alzheimer's disease. Hippocampus 21:1037-1044

38. Miermans CA, Kusters RP, Hoogenraad CC, Storm C (2017) Biophysical model of the role of actin remodeling on dendritic spine morphology. PLoS One 12:e0170113

39. Moolman DL, Vitolo OV, Vonsattel J-PG, Shelanski ML (2004). Dendrite and dendritic spine alterations in Alzheimer models. J Neurocytol 33:377-387

40. Nägerl UV, Eberhorn N, Cambridge SB, Bonhoeffer T (2004). Bidirectional activitydependent morphological plasticity in hippocampal neurons. Neuron 44:759-767.

41. Neuman KM, Molina-Campos E, Musial TF, Price AL, Oh KJ, Wolke ML, Buss EW, Scheff SW, Mufson EJ, Nicholson DA (2015) Evidence for Alzheimer's disease-linked synapse loss and compensation in mouse and human hippocampal CA1 pyramidal neurons. Brain Struct Funct 220:3143-65

42. Nishiyama J, Yasuda R (2015). Biochemical Computation for Spine Structural Plasticity. Neuron 87:63-75

43. Potier B, Billard J-M, Rivière S, Sinet P-M, Denis I, Champeil-Potokar G, Grintal B, 
Jouvenceau A, Kollen,M, Dutar P (2010). Reduction in glutamate uptake is associated with extrasynaptic NMDA and metabotropic glutamate receptor activation at the hippocampal CA1 synapse of aged rats: Synaptic effects of reduced glutamate uptake in the aged rat hippocampus. Aging Cell 9:722-735.

44. Pozueta J, Lefort R, Ribe EM, Troy CM, Arancio O, Shelanski M (2013). Caspase-2 is required for dendritic spine and behavioural alterations in J20 APP transgenic mice. Nat Commun 4:1939

45. Rasband W (1997) ImageJ, US National Institutes of Health, Bethesda, Maryland, USA. http://rsb.info.nih.gov/ij/

46. Scheff SW, DeKosky ST, Price DA (1990) Quantitative assessment of cortical synaptic density in Alzheimer's disease. Neurobiol Aging. 11:29-37

47. Scheff SW, Price DA (2003). Synaptic pathology in Alzheimer's disease: a review of ultrastructural studies. Neurobiol Aging 24:1029-1046

48. Scheff SW, Price DA, Schmitt FA, DeKosky ST, Mufson EJ (2007). Synaptic alterations in CA1 in mild Alzheimer disease and mild cognitive impairment. Neurology 68:1501-1508

49. Selkoe DJ (2002). Alzheimer's disease is a synaptic failure. Science 298:789-791

50. Selkoe DJ, Hardy J (2016). The amyloid hypothesis of Alzheimer's disease at 25 years. EMBO Mol Med 8:595-608

51. Sheng M, Sabatini BL, Südhof TC (2012) Synapses and Alzheimer's disease. Cold Spring Harb Perspect Biol 4:a005777

52. Sherrington R, Rogaev EI, Liang Y, Rogaeva EA, Levesque G, Ikeda M, Chi H, Lin C, Li G, Holman K, Tsuda T, Mar L, Foncin J-F, Bruni AC, Montesi MP, Sorbi S, Rainero I, Pinessi L, Nee L, Chumakov I, Pollen D, Brookes A, Sanseau P, Polinsky RJ, Wasco W, Da Silva HA, Haines JL, Perkicak-Vance MA, Tanzi RE, Roses AD, Fraser PE, Rommens JM, St George-Hyslop PH (1995). Cloning of a gene bearing missense mutations in early-onset familial Alzheimer's disease. Nature 375:754-760

53. Spires TL, Meyer-Luehmann M, Stern EA, McLean PJ, Skoch J, Nguyen PT, Bacskai BJ, Hyman BT (2005). Dendritic spine abnormalities in amyloid precursor protein transgenic mice demonstrated by gene transfer and intravital multiphoton microscopy. $\mathrm{J}$ Neurosci 25:7278-7287

54. Steele JW, Brautigam H, Short JA, Sowa A, Shi M, Yadav A, Weaver CM, Westaway D, Fraser PE, St George-Hyslop PH, Gandy S, Hof PR, Dickstein DL (2014) Early fear memory defects are associated with altered synaptic plasticity and molecular architecture in the TgCRND8 Alzheimer's disease mouse model. J Comp Neurol 522:2319-35

55. Tackenberg C, Brandt R (2009). Divergent Pathways Mediate Spine Alterations and Cell Death Induced by Amyloid-, Wild-Type Tau, and R406W Tau. J Neurosci 29:14439-14450 
56. Terry RD, Masliah E, Salmon DP, Butters N, DeTeresa R, Hill R, Hansen LA, Katzman R (1991). Physical basis of cognitive alterations in Alzheimer's disease: synapse loss is the major correlate of cognitive impairment. Ann Neurol 30:572-580

57. Tønnesen J, Katona G, Rózsa B, Nägerl UV (2014). Spine neck plasticity regulates compartmentalization of synapses. Nat Neurosci 17:678-685

58. Tønnesen J, Nägerl UV (2016). Dendritic Spines as Tunable Regulators of Synaptic Signals. Front Psychiatry 7:101

59. Viana da Silva S, Haberl MG, Zhang P, Bethge P, Lemos C, Gonçalves N, Gorlewicz A, Malezieux M, Gonçalves FQ, Grosjean N, Blanchet C, Frick A, Nägerl UV, Cunha RA, Mulle C (2016). Early synaptic deficits in the APP/PS1 mouse model of Alzheimer's disease involve neuronal adenosine A2A receptors. Nat Commun 7:11915

60. West MJ, Coleman PD, Flood DG, Troncoso JC (1994). Differences in the pattern of hippocampal neuronal loss in normal ageing and Alzheimer's disease. Lancet 344:769772 .

61. Wiegert JS, Oertner TG (2013). Long-term depression triggers the selective elimination of weakly integrated synapses. Proc Natl Acad Sci USA 110:E4510-E4519.

62. Wirths O, Breyhan H, Schäfer S, Roth C, Bayer TA (2008). Deficits in working memory and motor performance in the APP/PS1ki mouse model for Alzheimer's disease. Neurobiol. Aging 29:891-901.

63. Zou C, Montagna E, Shi Y, Peters F, Blazquez-Llorca L, Shi S, Filser S, Dorostkar MM, Herms J (2015). Intraneuronal APP and extracellular A $\beta$ independently cause dendritic spine pathology in transgenic mouse models of Alzheimer's disease. Acta Neuropathol 129:909-920. 


\section{Figure legends}

Fig. 1 Alteration of the morphology of dendritic spines in biopsies. a, b Ultrathin sections in the layers II-III of the frontal cortex of a non-AD (a) and an AD (b) patient. Spine synapses are indicated by asterisks. Spine necks in the plane of the section are indicated by arrows. c, d Examples of serial sections through a mushroom spine in a non-AD patient (c) and through a stubby spine in an AD patient (d). Spine synapses are indicated by asterisks. Spine necks in the plane of the section are indicated by arrows. e, f Examples of dendritic spines from a non-AD (e) and an $\mathrm{AD}$ (f) patient. Asterisks indicate spines having their neck in the plane of the section. Double arrows indicate the diameter of spine necks. $\mathbf{g}$ Linear regression of the density of synapses on the proportion of stubby spines. Scale bar in a: $1 \mu \mathrm{m}$ in a and b. Scale bar in c and $\mathrm{d}$ : $400 \mathrm{~nm}$. Scale bar in e: $500 \mathrm{~nm}$ in e and $\mathrm{f}$

Fig. 2 Decrease of neuronal and synaptic densities are preceded by an enlargement of dendritic spine necks. a, b Semithin sections through the CA1 pyramidal layer at 6 months in control PSI-KI (a) and APPxPS1-KI (b) mice. Amyloid plaques are indicated by arrows. The width of the stratum radiatum is indicated by a double arrow. c, d Quantification (mean+SEM) of the number of neuronal nuclei profiles per $220 \mu \mathrm{m}$-long portion of the pyramidal cell layer (c) and of the width of the stratum radiatum (d). e, f Ultrathin sections in the middle of the CA1 stratum radiatum at 6 months in PSI-KI (e) and APPxPS1-KI (f) mice. Asterisks indicate synaptic profiles. $\mathbf{g}$, h Quantification (mean+SEM) of the number of synaptic profiles on spines per $29 \mu \mathrm{m}^{2}$ (g) and of the length of PSDs (h). i, j Ultrathin sections through dendritic spines from PSI-KI (i) and APPxPS1-KI (j) mice at 3 months. Asterisks indicate spines having their neck in the plane of the section. Double arrows indicate the diameter of spine necks. k Quantification (mean+SEM) of the diameter of the neck of dendritic spines at 3 months. Scale bar in a: $100 \mu \mathrm{m}$ in a and b. Scale bar in e: 400 $\mathrm{nm}$ in e and $\mathrm{f}$. Scale bar in i: $500 \mathrm{~nm}$ in $\mathrm{i}$ and j. Difference between genotypes, *: $\mathrm{p}<0.05$, $* * *: \mathrm{p}<0.001$

Fig. 3 Measurement of dendritic spine morphological characteristics using 3D-spine reconstructions. a Serial sections through a dendritic spine from a PS1-KI mouse at 4 months. Asterisks indicate the head of the spine. b 3D reconstructions of dendritic segments from PS1-KI (arrows: spines with a thin neck) and APPxPS1-KI (arrowheads: 
spines with a large neck) mice at 3 months. $\mathbf{c}$ Criteria for the classification of spines as presenting or not a constriction. d Quantification (mean+SEM) over 50 sampled spines per mouse of the number of spines with or without a constriction at 3, 4 and 6 months of age. e, f Ultrathin sections through dendritic spines from a PS1-KI (e) and an APPxPS1-Ki (f) mouse. Double arrows indicate the diameter of spine necks and double dashed arrows indicate the length of the spines. g-i Quantification (mean+SEM) of the volume of dendritic spines (g), the length of spines (h), and the diameter of spine necks (i). Scale bar in a: $250 \mathrm{~nm}$. Scale cube in b: $0.2 \mu \mathrm{m} 2$ on a side. Scale bar in e: $500 \mathrm{~nm}$ in e and $\mathrm{f}$ Difference between genotypes, $*$ : $<<0.05, * *: p<0.01, * * *: p<0.001$

Fig. 4 Simulation of the impact of the alteration of spine morphology on the electrical and biochemical compartmentalization of spines. a Quantification (mean+SEM) of the electrical resistance of the spine neck ( $R_{\text {spine neck }}$ ) at 3 months. b Schematic of the NEURON model and simulation parameters. c Simulation of the effect of $50 \%$ reductions in $R_{\text {spine neck }}$ on EPSPs in the spine head (upper traces) or in the soma (lower traces). $\mathbf{d}$ Simulation indicating a $52 \%$ reduction in the time constant of diffusional equilibration of molecules across the spine neck in APPxPS1 KI mice. Difference between genotypes, *: $\mathrm{p}<0.05$

Fig. 5 Intact basal characteristics of synaptic function. a-d Extracellular recordings of afferent volley slopes (a), fEPSP slopes of non-NMDA synaptic potentials (b), pairedpulse facilitation (PPF) (c) and fNMDA amplitudes (d). For PPF measurement, the slope of the second response was normalized by the slope of the first response. e-g Patch clamp recordings of amplitude (e) and frequency (f) of miniature events (mEPSCs), and of the membrane resistance $(\mathrm{g})$

Fig. 6 Alteration of synaptic plasticity and memory performance. a LTP was induced by Theta Burst Stimulation at $\mathrm{t} 0$ after recording $15 \mathrm{~min}$ of baseline. LTP was then recorded during $60 \mathrm{~min}$. b LTD recorded after application of a low frequency stimulation. $\mathbf{c}$ Scheme of the NOL paradigm (Acquisition and Retention phases). nd1, nd2: non displaced objects; d: displaced object. d Graph of memory index. 33\% line: random performance. Difference between genotypes, $*: p<0.05, * *: p<0.01$ 

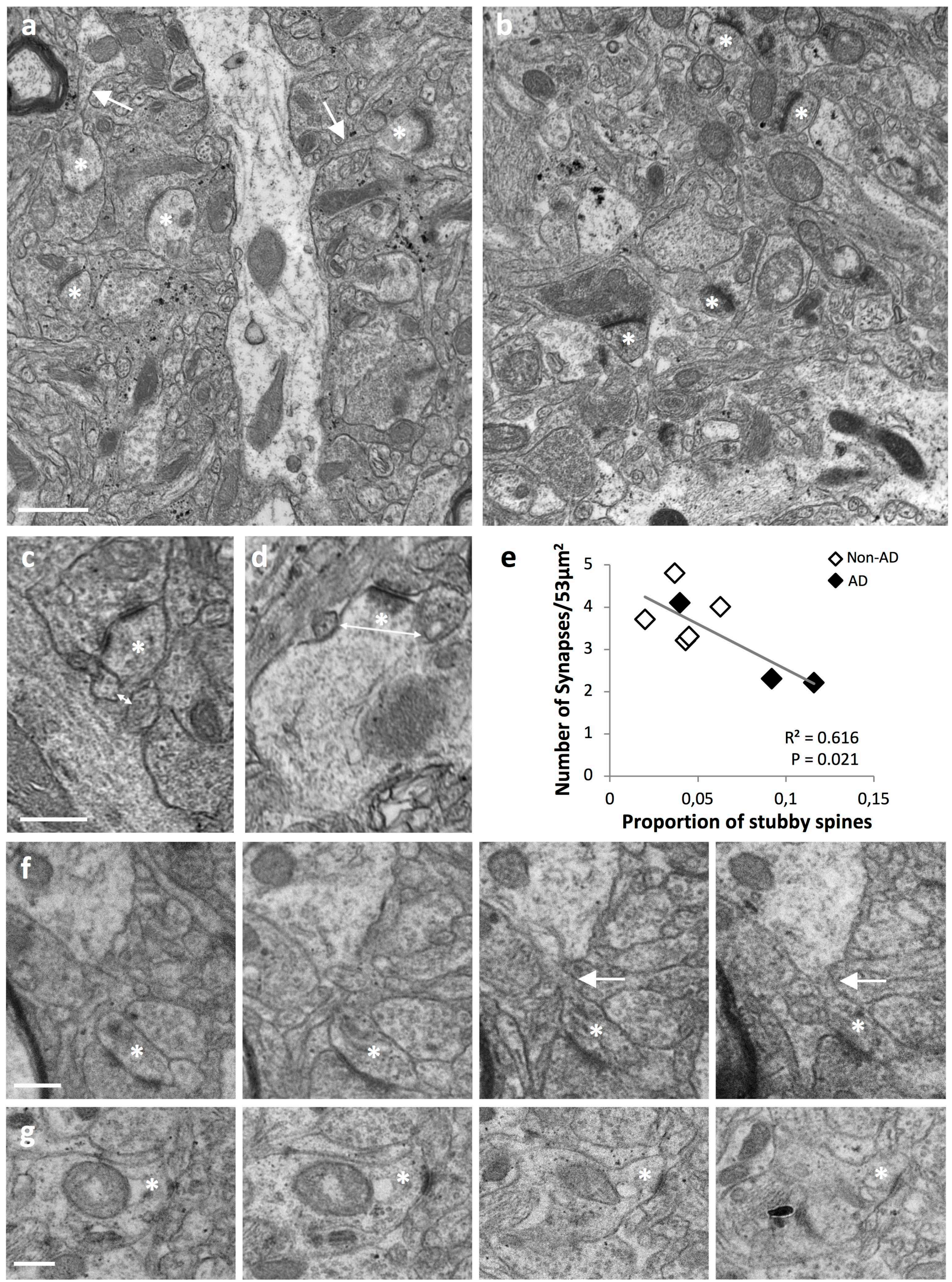

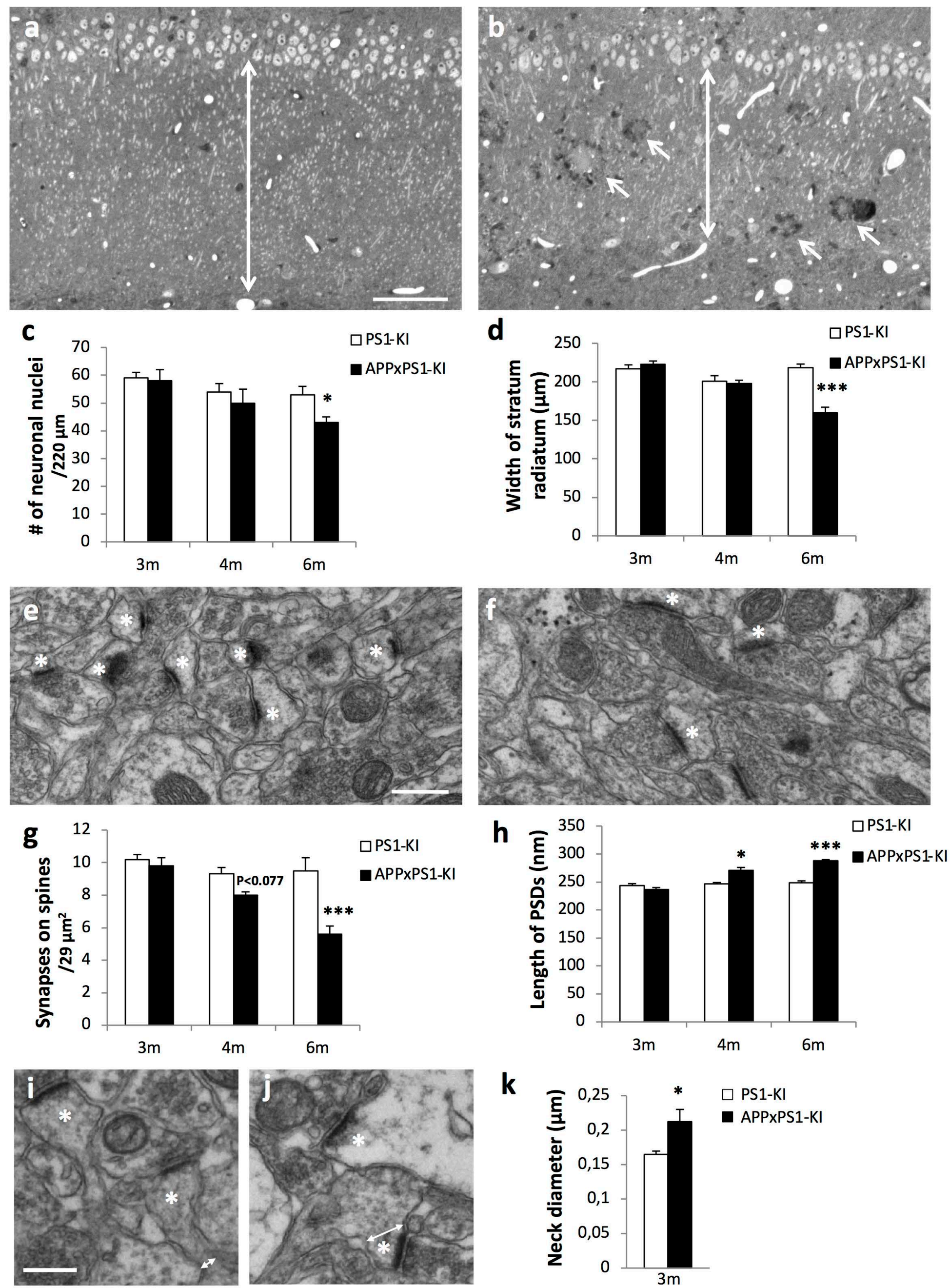
a

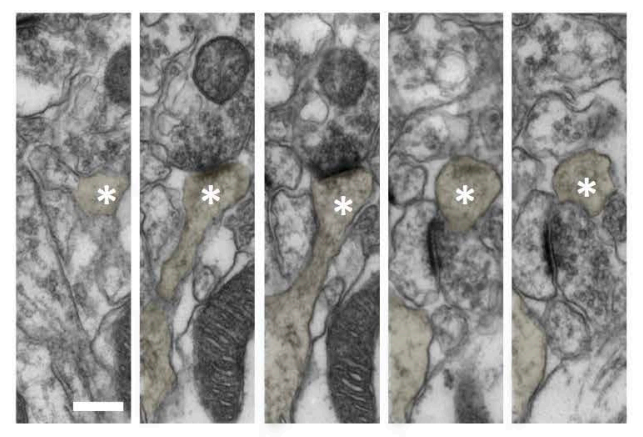

C

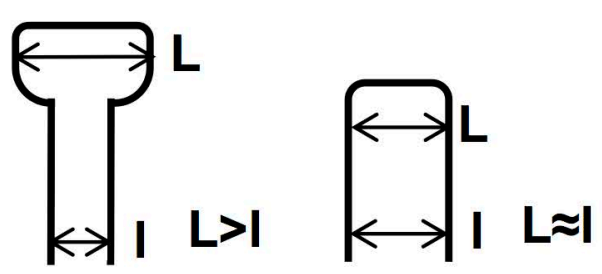

Constriction No constriction b
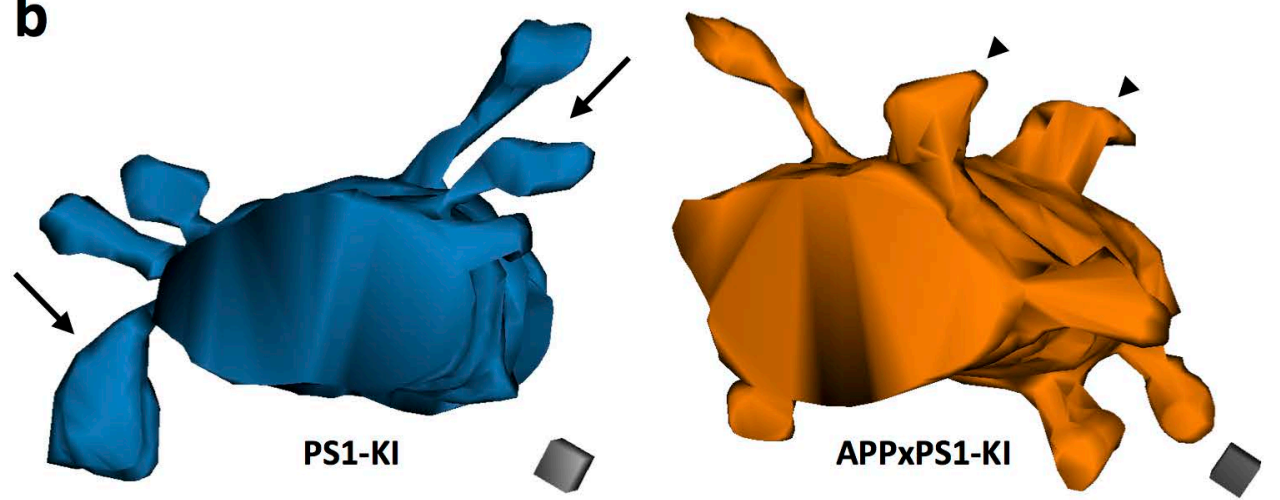

d

$\square$ Constriction

$\square$ No constriction
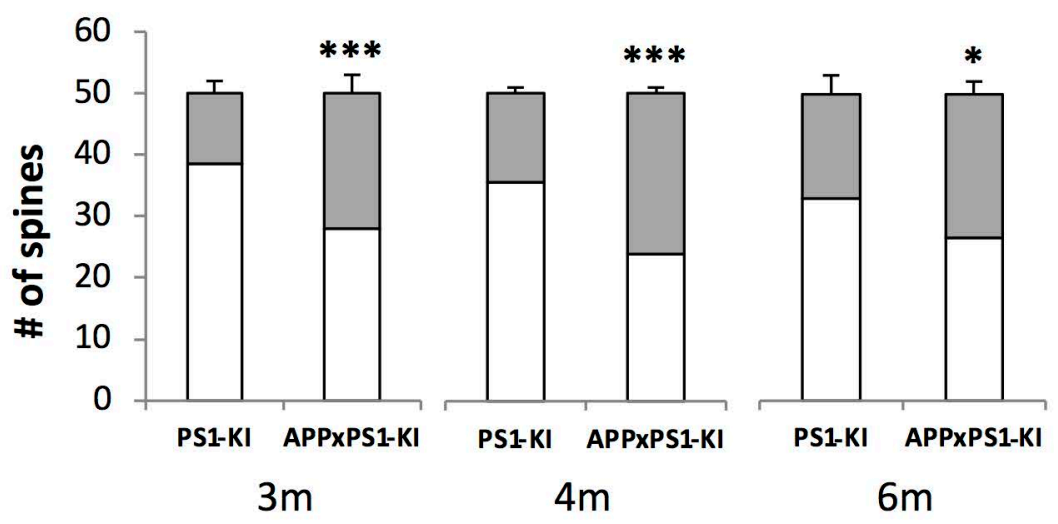

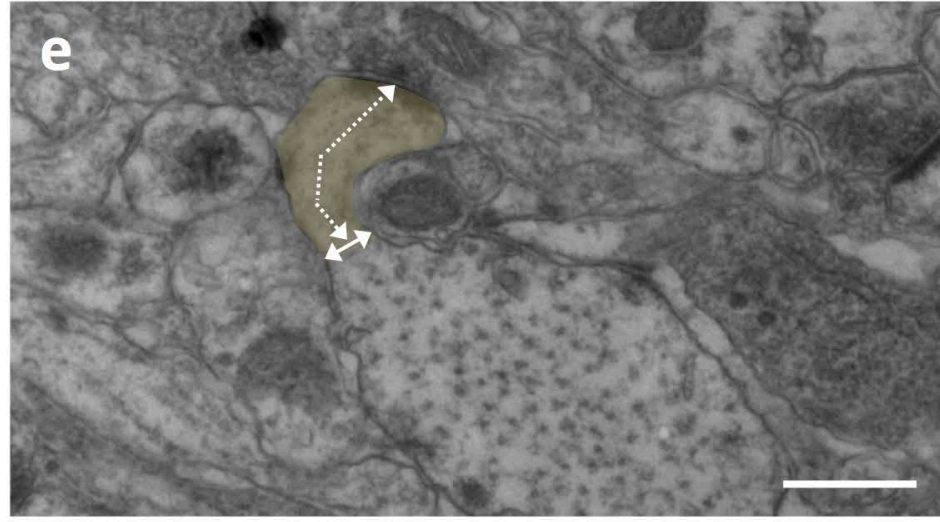

g

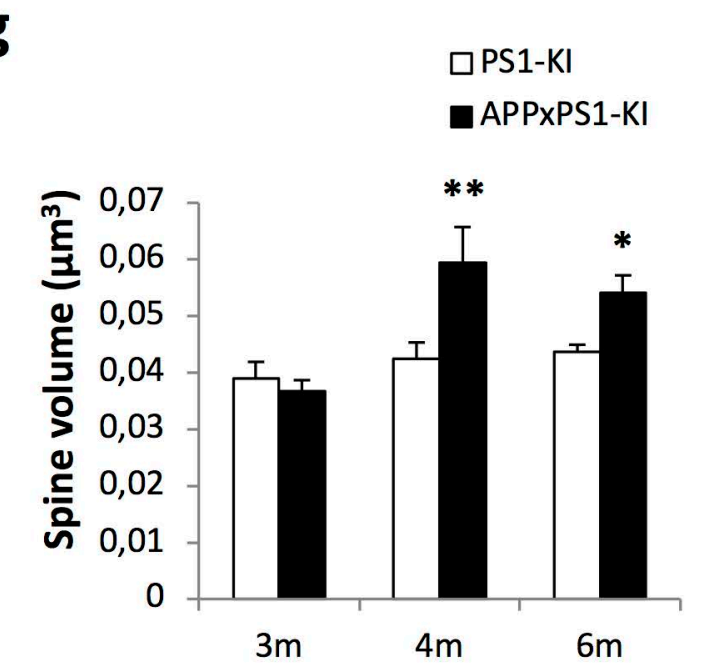

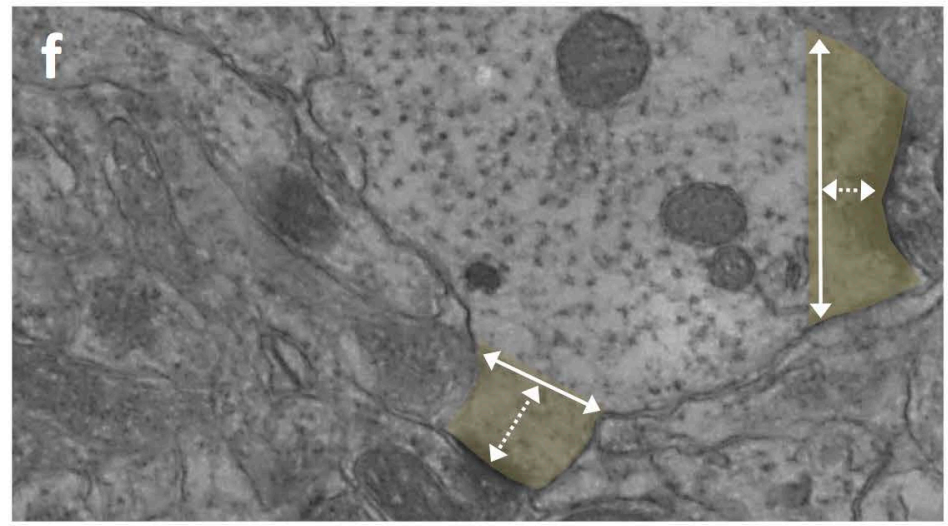

h

$\square$ PS1-KI

$\square$ PS1-KI

APPXPS1-KI

- APPXPS1-KI

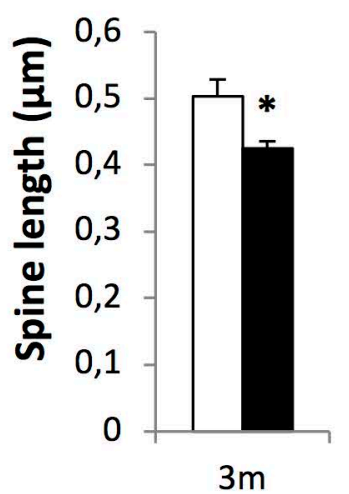


a
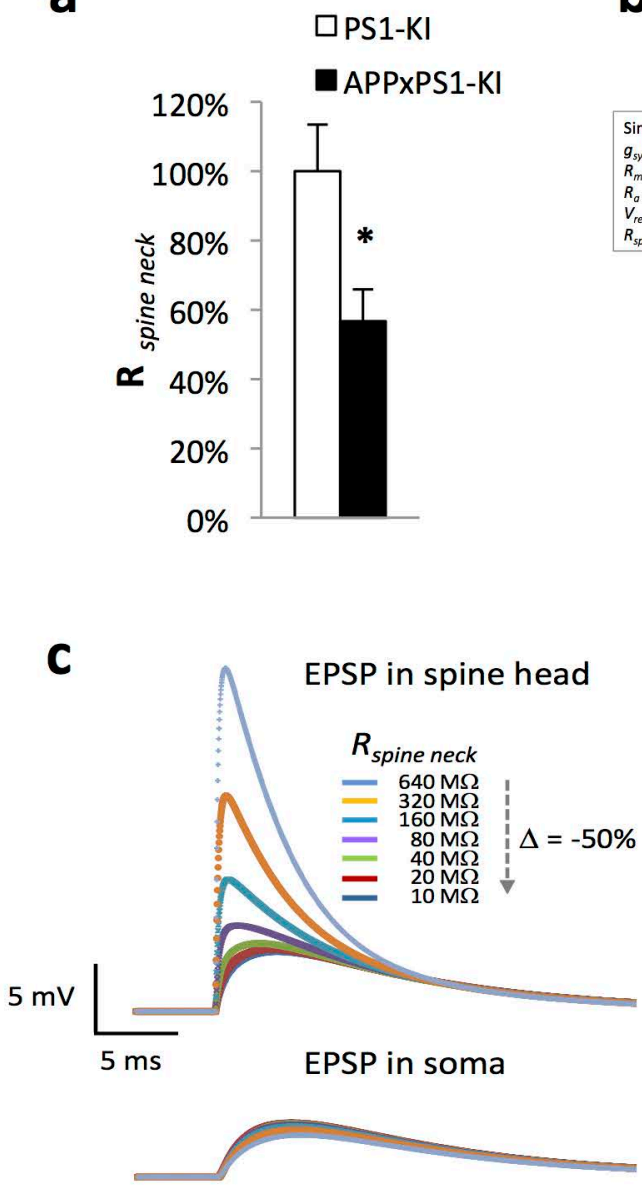

b
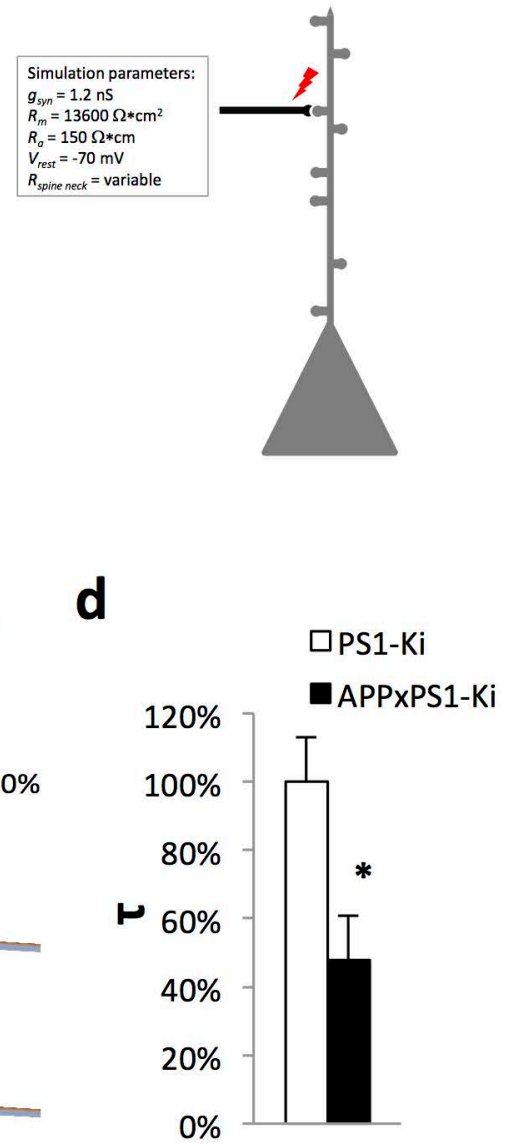
a

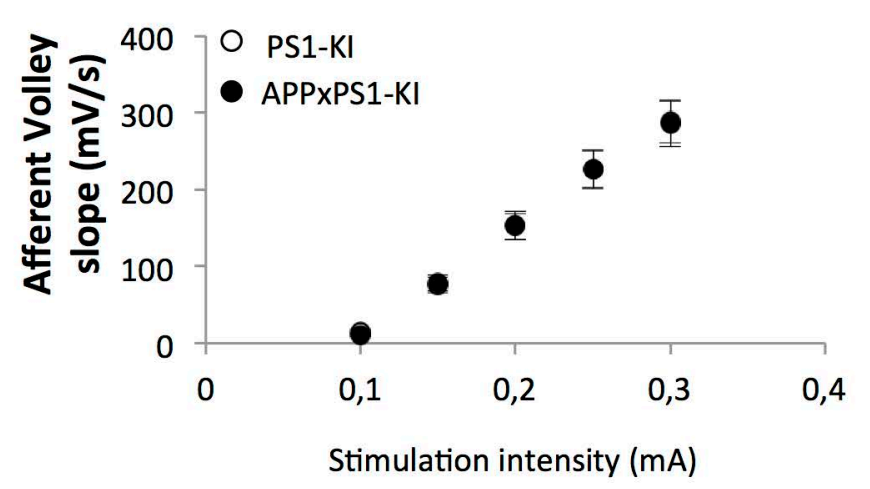

C

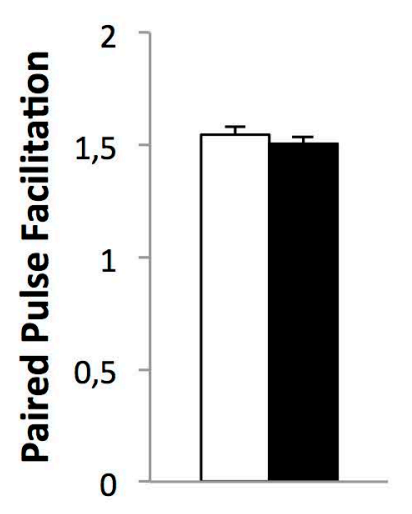

e

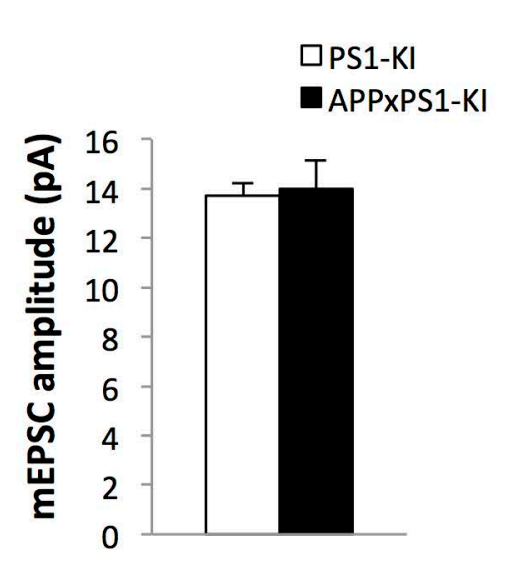

b

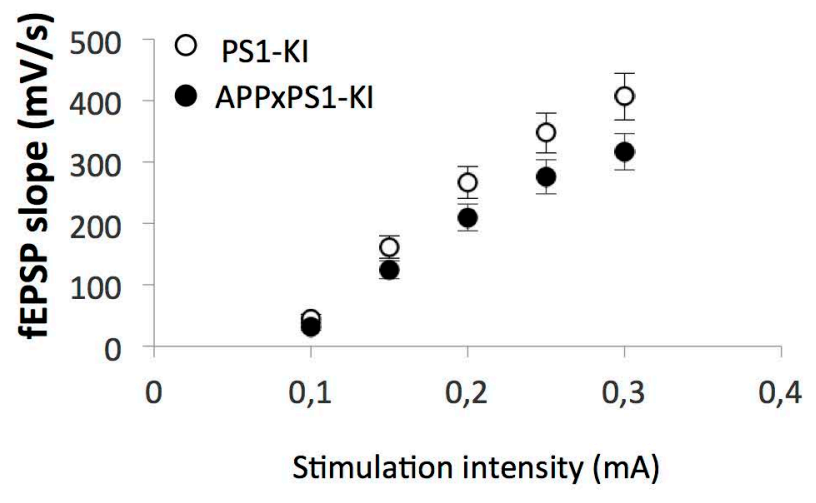

d

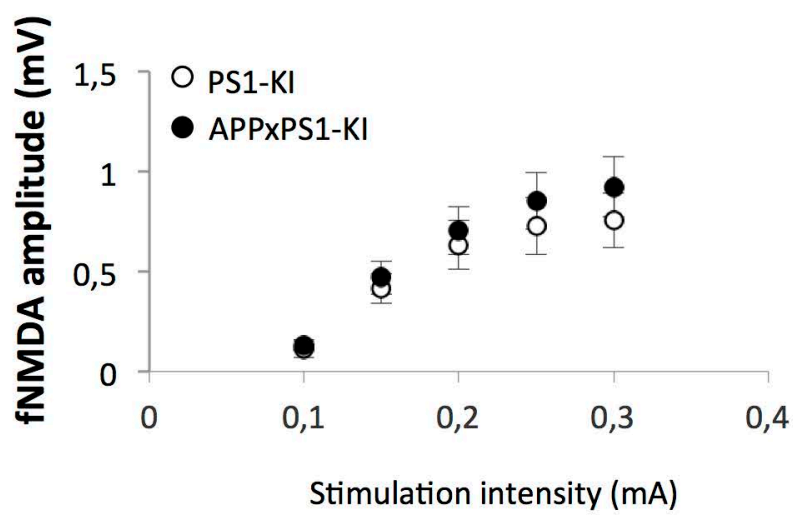

g

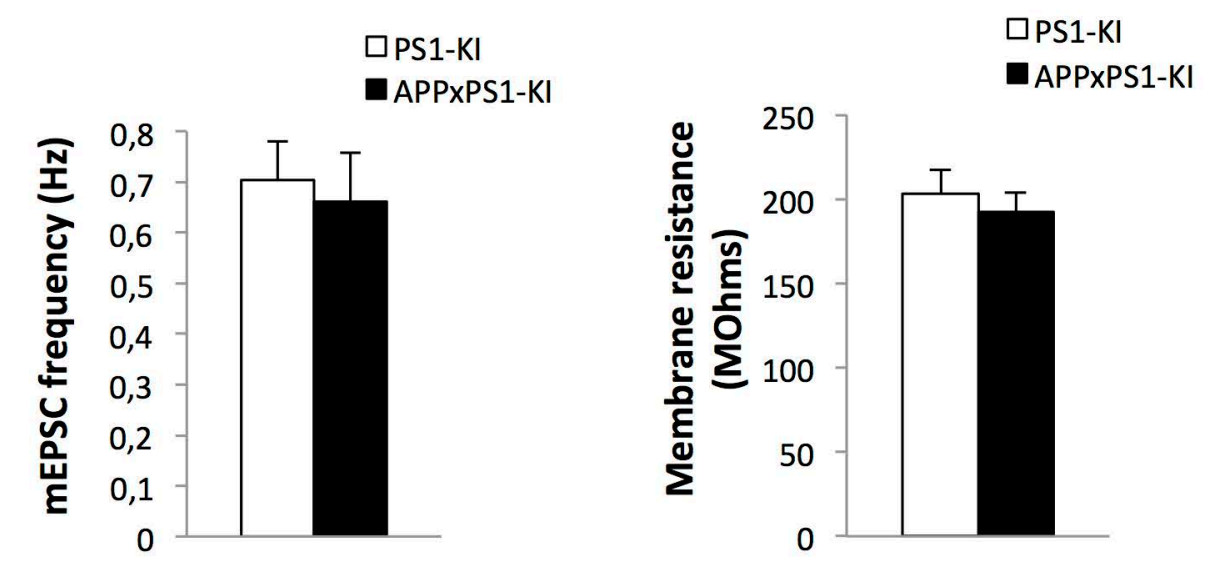


a

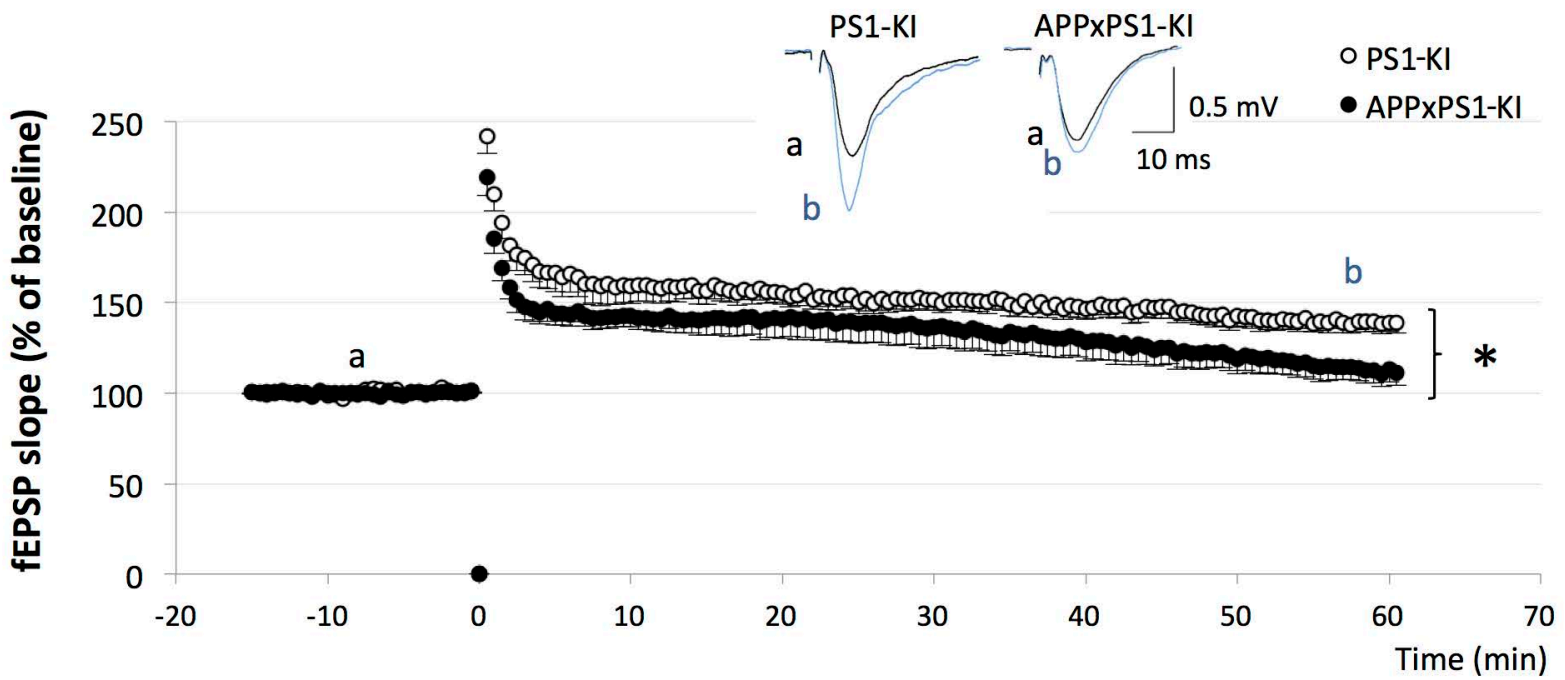

b

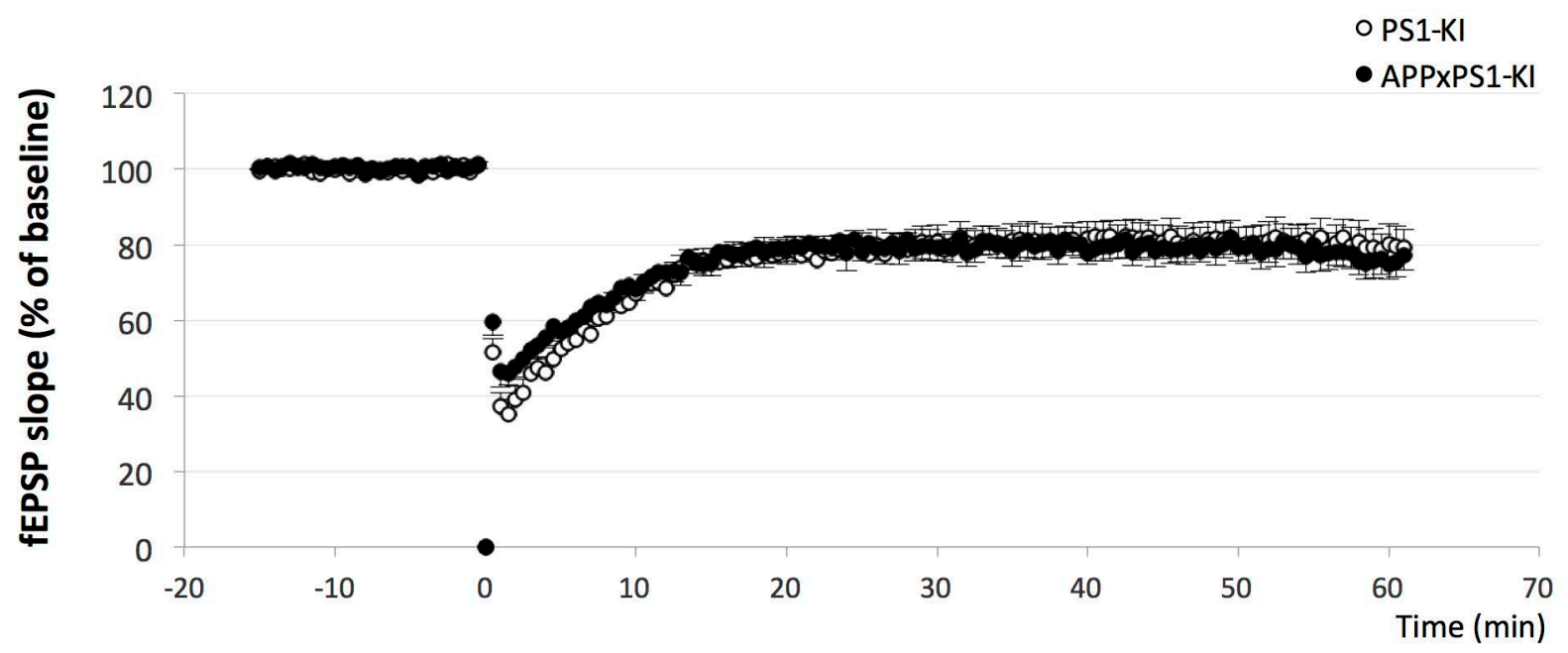

C

d

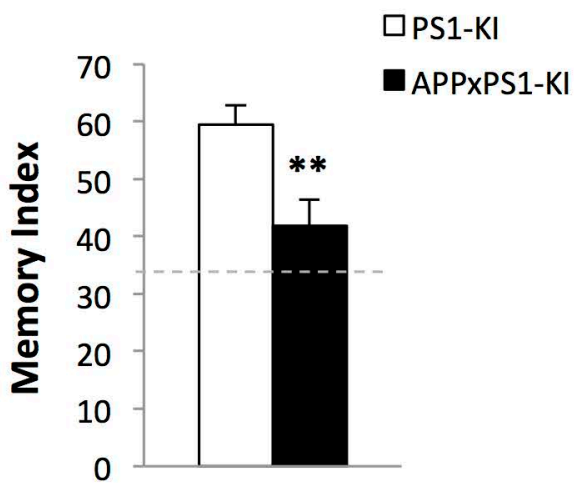

